Cómo citar este artículo / How to cite this article: Rodríguez Gutiérrez, O. y Jiménez Madroñal, D. (2019). Caracterización de un nuevo marmor polícromo bético explotado en época romana. Lucentum, XXXVIII, 255-280. http://dx.doi.org/10.14198/LVCENTVM2019.38.12.

\title{
CARACTERIZACIÓN DE UN NUEVO MARMOR POLÍCROMO BÉTICO EXPLOTADO EN ÉPOCA ROMANA*
}

\author{
A NEW BAETIC POLYCHROME MARMOR EXPLOITED IN ROMAN TIMES
}

\author{
OLIVA RODRÍGUEZ GUTIÉRREZ \\ Universidad de Sevilla \\ orodriguez@us.es \\ https://orcid.org/0000-0001-6795-7868 \\ DIEGO JIMÉNEZ MADROÑAL \\ Universidad de Sevilla \\ djm11294@gmail.com \\ https://orcid.org/0000-0003-3926-0945
}

Recepción: 28-03-2019

Aceptación: 15-05-2019

\section{Resumen}

El presente trabajo pretende dar a conocer, de forma más sistemática que las breves noticias parciales hasta ahora publicadas, una variedad de marmor polícromo empleado en época romana en construcciones y elementos en diferentes ciudades béticas, con especial concentración en el valle del Guadalquivir. El estudio incluye su caracterización petrográfica básica, así como la identificación de los principales contextos de uso, con valiosos datos tanto en lo que se refiere a la dispersión de los materiales como al volumen y naturaleza de la extracción. Asimismo se avanza en una propuesta de carácter territorial destinada a identificar los lugares más propicios para la ubicación de la cantera antigua, desconocida hasta la fecha, así como los resultados del posterior trabajo de campo realizado a partir de dichas hipótesis de localización.

Palabras clave. Marmor polícromo; caliza local; valle del Guadalquivir; Baetica romana; economía antigua.

\begin{abstract}
This work has the aim to present, in a more systematic way than previous brief notes in more general publications, a variety of polychrome marmor identified in several Baetic cities. Its use seems to be concentrate in the middle and lower Guadalquivir valley. The study includes a first petrographic characterization, as well as the indentification of the main contexts of use, which provide valuable data regarding material dispersion and the extent and nature of the exploitation. A location for the area of origin is also proposed, based on the analysis of the geological features of the region and the subsequent positive field survey.
\end{abstract}

Key words. Polychrome marmor; local limestone; Guadalquivir valley; Roman Baetica; ancient economy.

\footnotetext{
* Este trabajo se incluye en las líneas de interés del proyecto del PN de I+D+i La construcción en el Valle del Guadalquivir en época romana. Tradición e innovación en las soluciones arquitectónicas y los procesos tecnológicos, económicos y productivos (Trad-E) (HAR2015-64392-C4-4-P); igualmente se ha visto beneficiado de un contrato de técnico de apoyo a la investigación en el marco del Programa de Garantía Juvenil de la Junta de Andalucía y la Universidad de Sevilla.
} 


\section{INTRODUCCIÓN. SOBRE LOS MARMORA LOCALES, SU ALCANCE Y DISTRIBUCIÓN}

En las últimas décadas se ha producido un notable salto cuantitativo y cualitativo en la caracterización de las variedades de piedras ornamentales de ámbito local/ regional empleadas en época romana ${ }^{1}$.

Durante largo tiempo la investigación se volcó, casi exclusivamente, en las dinámicas asociadas a los marmora mediterráneos bajo control imperial (Fant, 1993; Pensabene, 2002; Russell, 2013: 4). Por un lado, porque se trataba de variedades en su mayor parte coloreadas y muy singulares (De Nuccio y Ungaro, 2002), macroscópicamente más fáciles de identificar y rastrear; por otro, porque una serie de fuentes como el Edictum De Pretiis dioclecianeo (Polichetti, 2001; Barresi, 2003: 157-158; Russell 2013: 33-36) o determinadas marcas y sellos sobre piezas en diferentes estadios de transformación o incluso en las propias canteras (Pensabene, 1994; 2002: 15-20; 2013: 35-42) parecían informar claramente de un monopolio imperial (Wilson, 2012: 139) ya sugerido en determinados pasajes literarios como los contenidos en las obras de Plinio (NH 36) o Suetonio (Tib. 49.2).

En la actualidad buena parte de estos lugares comunes han sido objeto de revisión, pudiendo hacerse dos importantes matizaciones: en primer lugar, todo parece indicar que materiales de las canteras imperiales accedieron, por diferentes vías y mecanismos, al libre comercio (Russell, 2013: 193-198); en segundo lugar, en la mayor parte de los territorios donde la geología puso a disposición piedras de cierta calidad para la arquitectura, la epigrafía o la ornamentación, estas fueron empleadas con mayor o menor difusión espacial. En algunos casos no llegaron más allá de la ciudad más próxima que, incluso, pudo explotarlas de acuerdo a una concesión municipal (Russell, 2013: 53-55; Rodríguez Gutiérrez, e.p.a) pero, en otros, su óptima calidad y posibilidades de gestión justificaron el empleo a cientos de kilómetros, en el marco de redes de intercambio de mucho mayor calado, como pueda ser el caso, para la península ibérica, del conocido como brocatello (Tortosa) (Mayer y Rodà, 1999; Àlvarez et al., 2009: 74-79) o algunas variedades de Almadén de La Plata (Sevilla) (Beltrán et al., 2011; 2012). Precisamente esa mayor difusión es la que ha llevado a algunos autores a proponer su carácter de canteras bajo control imperial (Rodà, 1997: 173-174; Beltrán et al., 2012: 272), en una suerte, lamentablemente, de razonamiento un tanto circular.

1. Baste mencionar, en ámbito internacional, las reuniones de la ASMOSIA, que se celebran cada dos/tres años y reúnen a los principales especialistas dedicados al estudio de las piedras ornamentales, tanto desde un punto de vista de sus usos y problemática antiguas, como de su caracterización arqueométrica a través de los avances de diferentes técnicas y disciplinas. Dos monografías recientes de síntesis, con bibliografía anterior, son las de P. Pensabene (2013) y B. Russell (2013).
Otro de los aspectos también discutidos en los últimos años tiene que ver con la datación del comienzo de las explotaciones. Las dificultades para identificar variedades marmóreas locales derivaban en la restitución apriorística y escasamente contrastada de las coyunturas económicas en el Mediterráneo romano. Según estas, el trabajo cualificado sobre piedras duras solo habría llegado a las provincias occidentales de la mano de los nuevos materiales imperiales y, con ellos, de artífices especializados. Por tanto, era prácticamente imposible esperar encontrar una tradición de cantería de calidad asociada a marmora con anterioridad a la creación de la ratio marmorum augustea, la organización de las canteras por Tiberio o el acceso a las tradiciones egipcias del trabajo de la piedra, con la inclusión de las canteras del desierto oriental en la propiedad imperial, en tiempos de Claudio (Padilla, 2000; Pensabene, 2002: 17 y $23-26)$.

Hoy sabemos que fueron numerosas las canteras en diferentes puntos del Occidente romano que se pusieron en uso en momentos tempranos (Pensabene, 2002: 3-4). Ello implica, por tanto, unos considerables y especializados conocimientos técnicos de la cantería, así como capacidad logística y organizativa tanto de cantera como de transporte y distribución de los materiales (Ward Perkins, 1992).

Sin duda el caso de la Bética, objeto de intensas investigaciones recientes, resulta paradigmático en esta línea (Beltrán y Rodríguez Gutiérrez, 2011; Beltrán et al., 2011). El análisis en paralelo tanto de las canteras de origen como de las ciudades y yacimientos de destino ha propiciado la caracterización de los circuitos seguidos por los materiales y, en la medida de lo posible, el período aproximado de funcionamiento y uso. Si el momento de finalización de las explotaciones es más difícil de establecer debido al intenso reempleo sufrido por las piezas y a las dificultades para identificar un uso primario o secundario de la piedra, mayores precisiones parecen existir con el de puesta en explotación. En cualquier caso, las evidencias arqueológicas permiten establecer términos post quem de cierta validez. De esa forma, todo parece indicar que variedades como las de Almadén de La Plata, Mijas y Alconera ya eran explotadas en época augustea (Beltrán y Rodríguez Gutiérrez, 2011; Rodríguez Gutiérrez, e.p.b). Más aún, el hecho de que en esa datación se den cita conjuntamente en un mismo edificio, el teatro romano de Itálica (Rodríguez Gutiérrez, 2008), denota la capacidad organizativa y logística de la obra y la capacidad de respuesta de las canteras ya para estas fechas.

\section{EL MÁRMOL POLÍCROMO DEL VALLE DEL GUADALQUIVIR. ESTADO DE LA CUESTIÓN}

Es en este panorama de mejor caracterización de los marmora locales en el que tiene sentido abordar una variedad como la que aquí se presenta (Fig. 1). 

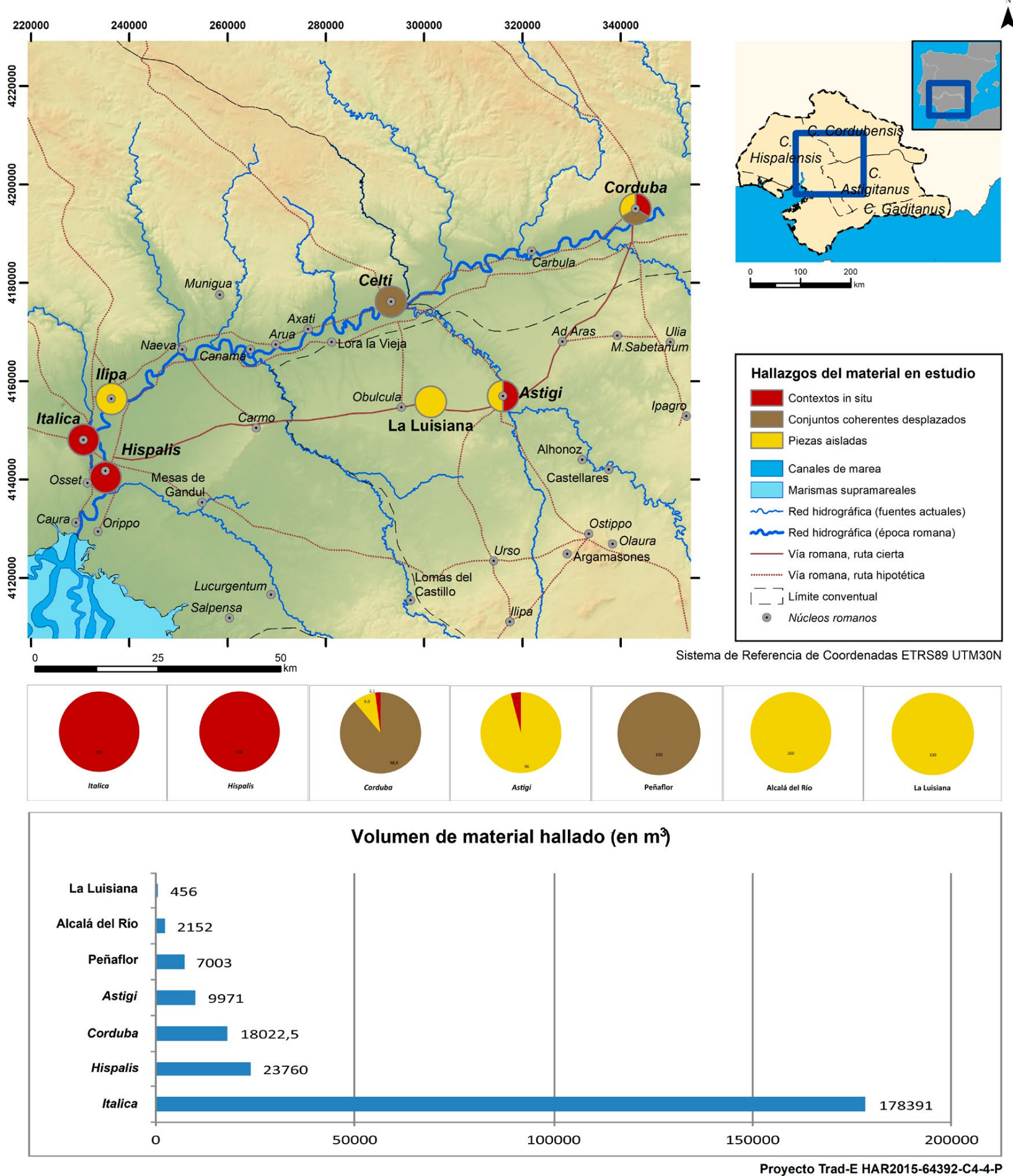

Figura 1: Mapa de dispersión de elementos arqueológicos realizados en el marmor objeto de estudio y gráficos de análisis cuantitativo del volumen de material con respecto al tipo de hallazgo

En un rastreo inicial cabe identificarlo con el puntualmente denominado «mármol de Peñaflor» (Rodríguez Gutiérrez, 2008: 251, n. ${ }^{\circ}$ 53), por haber sido en el entorno de esta localidad actual -solar de la antigua Celti- donde por primera vez ha sido reconocido en materiales arqueológicos (Keay et al., 2001: 250; Pensabene, 2013: 478 y fig. 12.7), aunque descontextualizados o en posición secundaria. No obstante, no parece tratarse, en ningún caso, de una identificación realizada en cantera, sino en piezas de naturaleza arqueológica.

No obstante, fue en el ya citado teatro romano de Itálica (n. ${ }^{\text {os }} 1$ a 6) (Rodríguez Gutiérrez, 2008: 251253) donde se tomó por primera vez conciencia de la envergadura y relevancia de la explotación, al documentarse in situ grandes bloques de este material, 


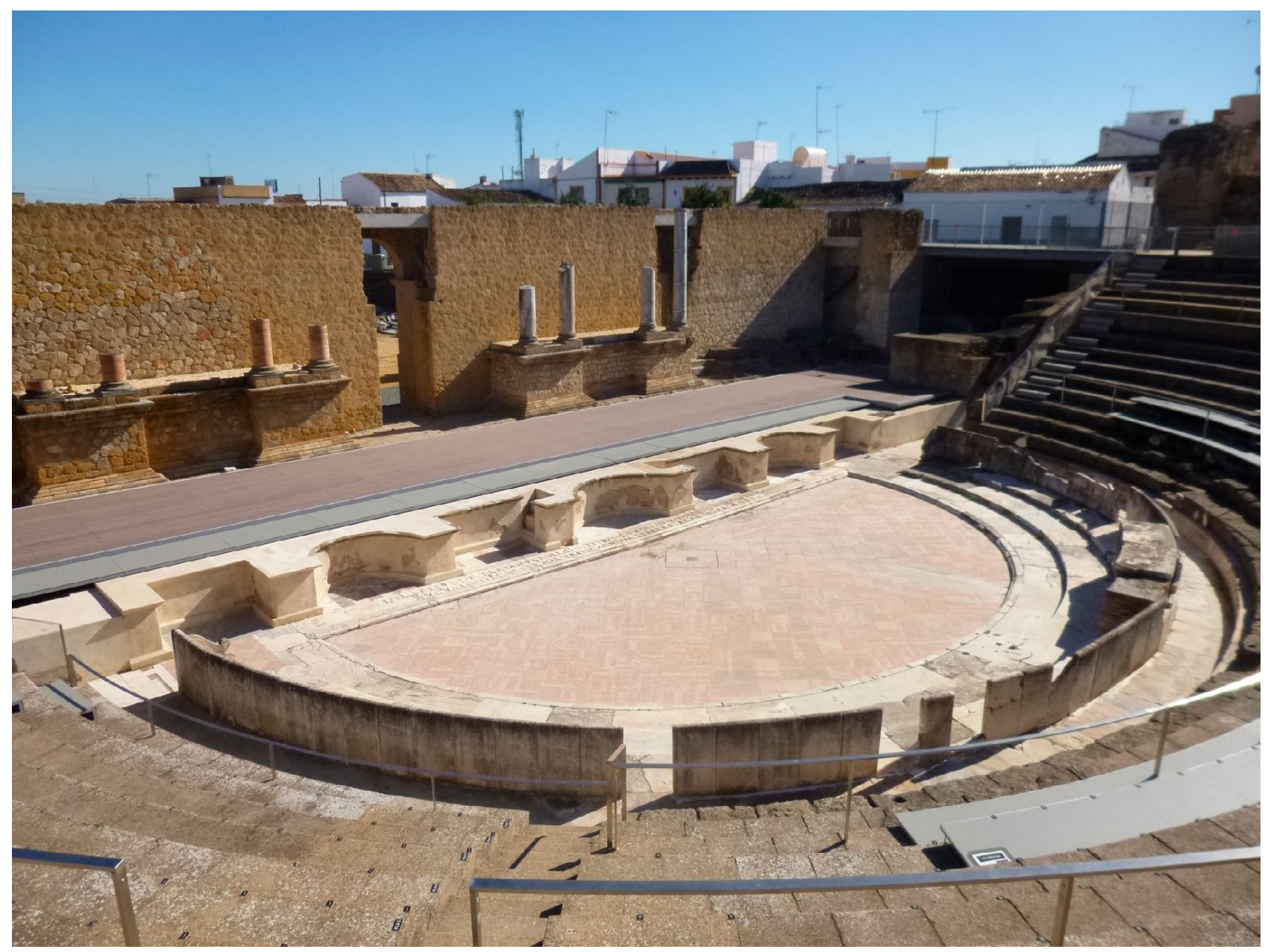

Figura 2: Vista de la orchestra del teatro romano de Itálica, donde el mármol objeto de estudio fue empleado en la praecinctio inferior y el primer escalón de unión con la ima cavea

formando parte del pavimento de la praecinctio de separación de la proedria y la ima cavea, así como en el pequeño escalón macizo corrido, en la base de esta última (Fig. 2). Las considerables dimensiones de estas losas, así como la complejidad de su despiece llamaron la atención sobre la amplitud del frente de cantera de origen, descartando, por tanto, un uso residual de afloramientos pétreos; también, la presencia ya de un trabajo especializado de la piedra en este momento de construcción del edificio, en tiempos augusteos. Fue igualmente a lo largo de estos más de $37 \mathrm{~m}$ de recorrido de la praecinctio donde se pudo poner de manifiesto la variabilidad cromática e incluso estructural, a nivel macroscópico, de esta piedra caliza, resultado de su compleja formación geológica. Como se aprecia aún mejor en la losa de umbral conservada en el atrio de la iglesia ecijana de Santa María (n. ${ }^{\circ}$ 17, Fig. 3), el material, muy veteado, podía presentar a la vez tonalidades blancas, verdosas, amarillentas, rosadas y violáceas en una superficie limitada.

El interés científico por este marmor, cuya valoración en época romana como material constructivo/ ornamental ya quedaba fuera de toda duda al aparecer conjuntamente con otras valiosas variedades locales como los blancos de Mijas o Almadén, aumentó al identificarlo como soporte de algunas piezas epigráficas singulares, así como de elementos arquitectónicos de gran porte, como algunos fustes monolíticos reutilizados en la Mezquita de Córdoba (n. ${ }^{\circ}$ 14) o un altar cilíndrico con dedicación a Augusto procedente de Córdoba (n. $\left.{ }^{\circ} 15\right)$. Del mismo modo, al realizar una primera aproximación a la dispersión geográfica de las piezas conocidas, esta parecía concentrarse, claramente, en una región en torno a los valles medio y bajo del Guadalquivir (Fig. 1).

No obstante, a falta de un estudio en mayor profundidad como el que aquí por primera vez se trata de realizar, esta variedad marmórea, al margen de breves alusiones (Rodríguez Gutiérrez, 2008: 251-253; Beltrán y Rodríguez Gutiérrez, 2011: 565), no ha quedado incluida en los estudios recientes de caracterización de las canteras béticas de piedras ornamentales (Beltrán et al., 2011; Beltrán et al., 2012).

En cualquier caso, de ese primer acercamiento se obtenía que esta piedra polícroma contaba con todas las características para ser considerada una variedad en sí misma y con personalidad propia ya en tiempos antiguos: 


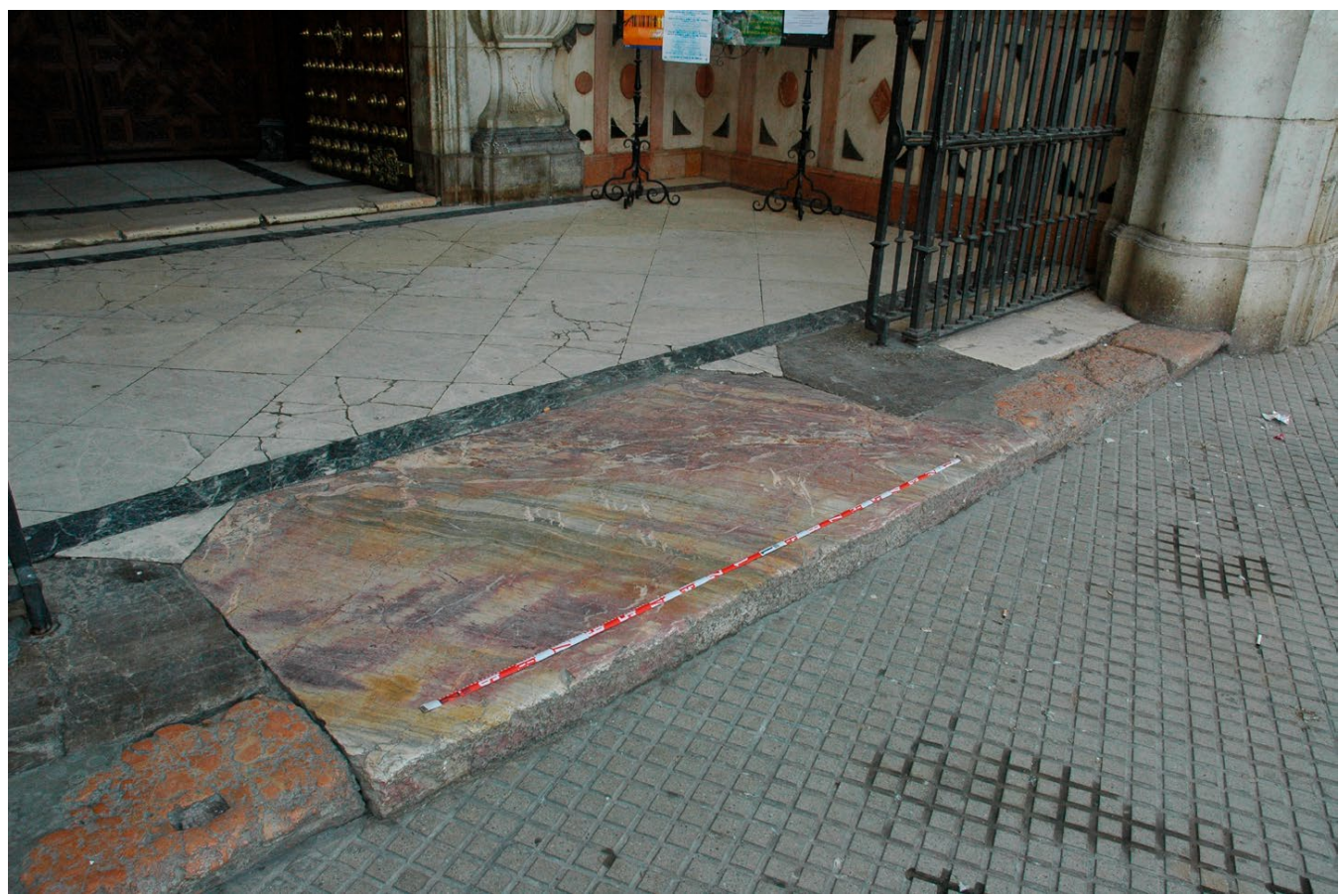

Figura 3: Umbral de acceso al pórtico de la actual iglesia de Santa María en Écija (Sevilla)

a) se explotaba en una cantera de envergadura considerable en la que se contaba con un conocimiento especializado del trabajo de la piedra, que permitía obtener grandes bloques de buena calidad, ya desde aproximadamente el cambio de Era.

b) era un material valorado y demandado por los clientes y promotores de las obras, elegido como soporte de realizaciones singulares de importante valor simbólico y estético.

c) posee una probada dispersión regional con presencia en algunas de las más importantes ciudades del occidente bético, donde el hilo conductor parece ser el cauce del río Guadalquivir.

Visto lo anterior, a continuación se procederá a analizar los diferentes aspectos que permitan una adecuada caracterización del material. Se comenzará por sus características físicas y petrográficas, se revisarán los contextos arqueológicos más singulares y coherentes, insistiendo en los datos formales del soporte y cronológicos que puedan aportar información sobre la producción. Por último, se llevará a cabo un ensayo de localización de la cantera de origen a partir de la contrastación de los datos obtenidos de los análisis arqueométricos y los proporcionados por la naturaleza geológica de la región, con constatación a través de trabajo de campo in situ.

\section{CARACTERIZACIÓN DEL LITOTIPO}

Como ya se ha indicado más arriba, este material pétreo resulta actualmente singular -como también lo hizo en el pasado- por las muy diferentes tonalidades que puede ofrecer en una superficie reducida. Esto evidencia la variedad textural y composicional que deben presentar los afloramientos geológicos asociados a estas canteras, dada la heterogeneidad visual que presentan. Ello, muy probablemente, hacía de él un material valorado desde el punto de vista estético, a lo que se sumaba su dureza y densidad. De hecho, como se verá más adelante, uno de sus principales usos parece haber sido el de grandes losas pavimentales (n. ${ }^{\text {ss }} 1,3,7,8,11$ y 17). Esas mismas características podían, no obstante, resultar menos favorables para otras funciones. Así, la elevada compactación dificultaría la ejecución de detalles, de ahí que hasta el momento, la mayor parte de las piezas documentadas respondan a volúmenes fundamentalmente geométricos o, en menor medida, con molduras sencillas. Parece clara su no idoneidad para la ejecución de lastras delgadas, aplacados, escultura y, en general, piezas de pequeño tamaño. Tampoco favorecería las labores de tallado la diferencial respuesta de los componentes de la piedra a la percusión. Por último, la variabilidad cromática, con coloraciones ocasionalmente bastante oscuras, podría comprometer la legibilidad de mensajes epigráficos. No obstante, el que a pesar de ello se eligiera como soporte de diferentes inscripciones (n. ${ }^{\text {os }} 6,9,13,15$ y 18 ) denota que, en esos casos, primaron sus valores estéticos sobre los prácticos.

Aunque su aspecto macroscópico hace pensar en un mármol, sensu stricto es una caliza microesparítica diagenetizada, sometida a un metamorfismo de grado bajo, con indicios claros de deformación (Àlvarez et al., 2006: 4).

Desde el punto de vista visual, esta caliza se caracteriza por presentar textura micrítica y bandeado 


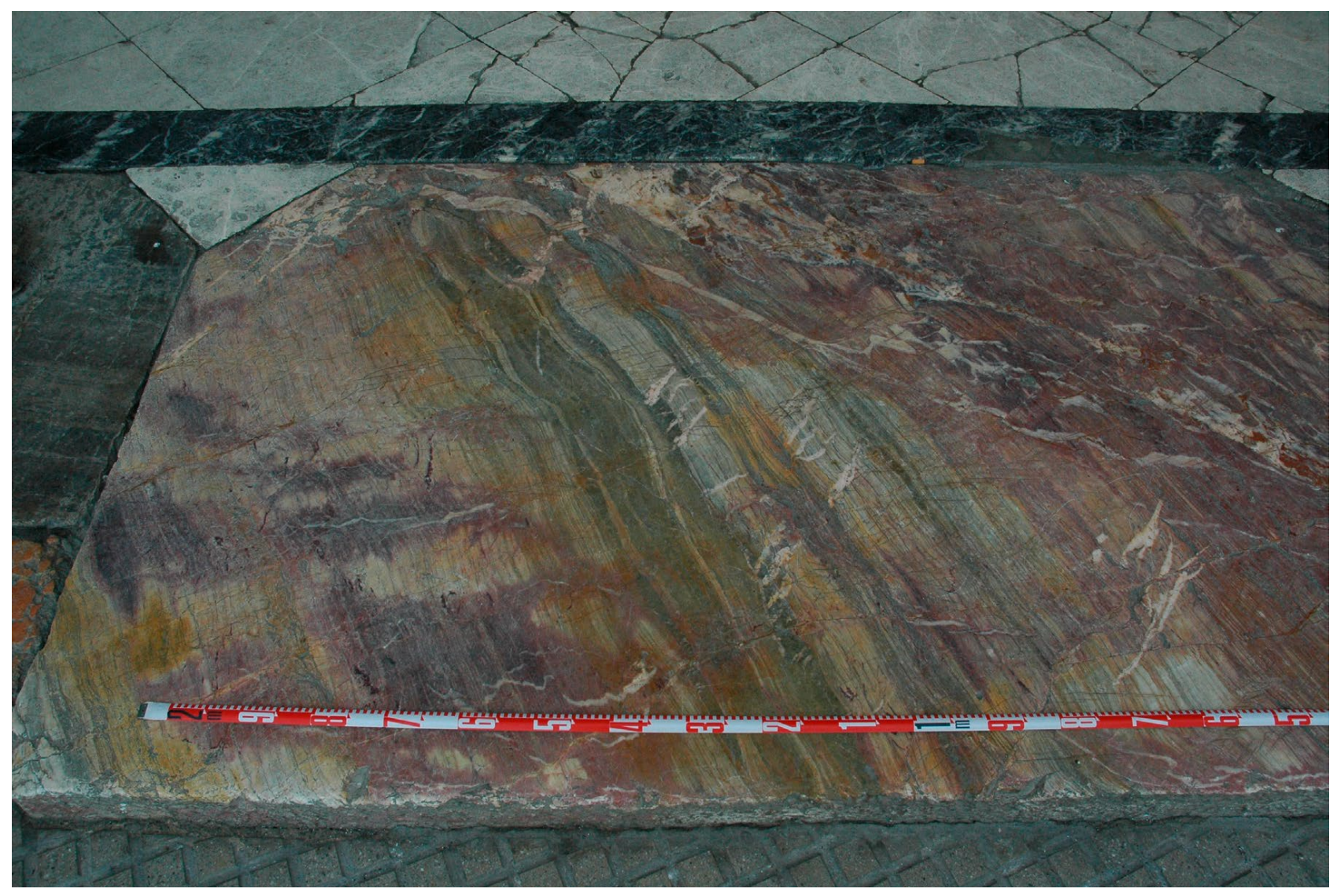

Figura 4: Detalle del material de la losa reutilizada como umbral en la iglesia de Santa María de Écija

composicional que define distintos niveles cromáticos, de grosor variable, que han sufrido plegamiento. Estas variedades de color se deben, en lo que a su composición respecta, a aportes de sedimentos con diferentes condiciones de depósito desde su origen, sometidas posteriormente a procesos metamórficos. Si bien las piezas arqueológicas identificadas corresponden a calizas compactas, es frecuente observar intercalaciones más arcillosas que le confieren menor dureza. Las tonalidades que predominan son fundamentalmente rosado-granates y verdosas, pudiendo contener matices blanquecinos, violáceos y amarillentos (Fig. 4).

Desde el punto de vista petrográfico ${ }^{2}$ (Figs. 5 y 6) la roca corresponde a una caliza microesparítica

2. Los análisis se han realizado en un primer momento en el marco, entonces, del proyecto del PN I+D+i HUM200502564 Arqueología de las ciudades romanas de la Bética, bajo la dirección de J. Beltrán Fortes, en la Unitat d'Estudis Arquèometrics del Institut Català d'Arqueologia Clàssica (Tarragona). Con posterioridad ulteriores caracterizaciones petrográficas de muestras del mismo material se han llevado a cabo en el Laboratorio de Geología del IAPH (Sevilla) en el marco de diferentes proyectos de investigación, como pueda ser el dedicado a la epigrafía astigitana (HAR2009-08823, dir. S. Ordóñez Agulla). Agradecemos a Esther Ontiveros la revisión última de estos aspectos relativos a la caracterización petrográfica del litotipo estudiado, así como sus inestimables consejos sobre la presentación de los datos geológicos. diagenetizada con importante aporte de material detrítico, una laminación incipiente a favor de los planos de estratificación mineralizada con óxidos de hierro (Àlvarez et al., 2006: 3) y, en algunos casos, desarrollo de superficies estilolíticas. En lo que a la mineralogía se refiere, las diferentes muestras contienen calcita, dolomía, plagioclasas, moscovita, diferentes minerales opacos así como cristales de cuarzo diseminados por la matriz, distribuidos en sentido paralelo. Según los casos, estos últimos pueden presentar extinción ondulante con inclusiones de rutilo.

\section{CONTEXTOS MATERIALES, EMPLEO Y DIS- PERSIÓN (FIG. 7)}

En este apartado se presentarán los materiales arqueológicos identificados hasta el momento en esta variedad pétrea. Para dicha revisión se han distinguido tres grupos, de acuerdo a la diferencial información contextual que ofrecen. En un primer grupo se incluyen materiales recuperados o conservados in situ, asociados a edificios o yacimientos concretos. Ello permite conocer la funcionalidad precisa de las piezas así como su combinación conjuntamente con otras variedades. Del mismo modo serán muy valiosos para caracterizar otros ejemplares semejantes sin contexto arqueológico conocido. Un segundo grupo recoge conjuntos de piezas, con cierta coherencia, en posición secundaria y que, muy 

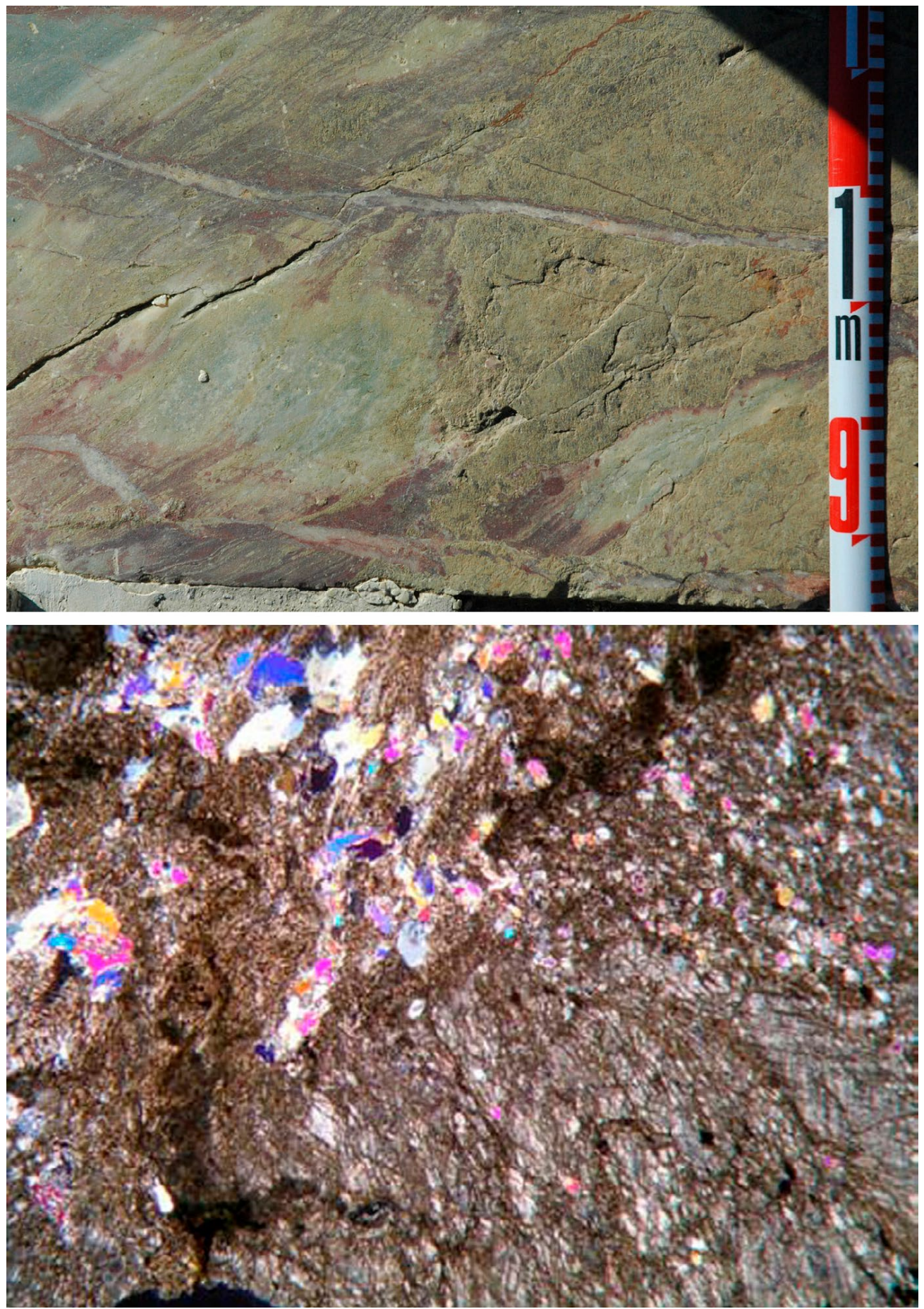

Figura 5: Microfotografía de muestra tomada de una de las losas del pavimento de la praecinctio inferior del teatro romano de Itálica (2X NC, M3-ITA0238, ICAC)

probablemente, no distan en exceso de su lugar original de uso. Por último, un tercer grupo lo componen piezas aisladas descontextualizadas, cuya localización, aunque más genérica, será igualmente tenida en cuenta. El repertorio, por tanto, no tiene vocación de catálogo exhaustivo y es deseable que crezca, precisamente, a partir de ahora, con la mejor caracterización del litotipo. No obstante, es un conjunto lo suficientemente numeroso y variado para llegar a interesantes conclusiones sobre el uso y naturaleza del material.

\subsection{Primer GRUPO: CONTEXTOS IN SITU}

\subsubsection{Teatro romano de Itálica}

El primer contexto, sin duda entre los de mayor interés por el número y variedad funcional de las piezas, es el teatro romano de Itálica.

El mármol polícromo objeto de estudio fue empleado en el pavimento de la praecinctio inferior de separación de la orchestra (proedria) y la ima cavea (Rodríguez 

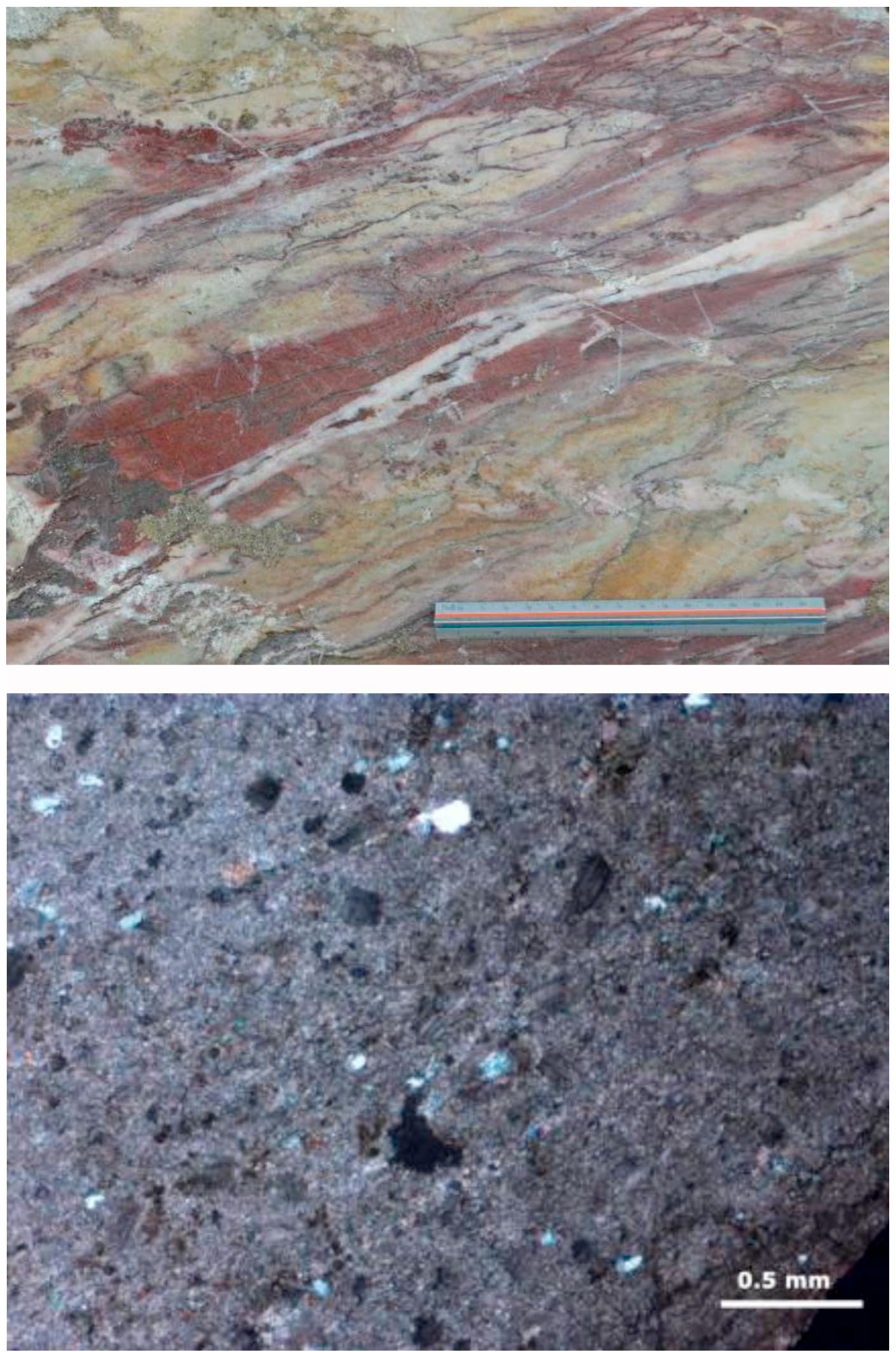

Figura 6: Microfotografía de muestra tomada de una de las losas del pavimento del edificio excavado en el número 17 de la calle Goyeneta (Sevilla) (G-13, IAPH, con escala gráfica)

Gutiérrez, 2004: 80, n. 22; 2008: 237, tabla 1, 251; Beltrán y Rodríguez Gutiérrez, 2011: 565, n. ${ }^{\circ} 53$ ) (n. ${ }^{\circ}$ 1). Son grandes bloques de forma paralelepipédica de despiece heterogéneo. Se conservan in situ, exhumados en el curso de las excavaciones de la década de los setenta del siglo pasado; 34 de las 39 losas son originales. Ofrecen dimensiones diferentes, siendo las de mayor tamaño de $120 \times 170 \mathrm{~cm}$. Se suceden a lo largo del arco de la media circunferencia que forma la orchestra, de aproximadamente $37 \mathrm{~m}$ lineales (Figs. 2 y 8). Es notable la pericia técnica con la que se ejecuta el conjunto, más aún teniendo en cuenta dicha heterogeneidad en dimensiones y cortes; de hecho, estos no confluyen hacia el centro del semicírculo de la orchestra en torno 


\begin{tabular}{|c|c|c|c|c|c|c|c|}
\hline & $\mathrm{N}^{0}$ & IDENTIFICACIÓN & $\begin{array}{l}\text { MEDIDAS } \\
(\mathrm{en} \mathrm{cm})\end{array}$ & $\begin{array}{l}\text { PROCEDENCIA/ } \\
\text { LOCALIZACIÓN }\end{array}$ & $\begin{array}{l}\text { OTRAS } \\
\text { REFS. }\end{array}$ & $\begin{array}{l}\text { DATACIÓN } \\
\text { ESTIMADA }\end{array}$ & $\begin{array}{c}\text { CÓD. } \\
\text { MUESTRA }\end{array}$ \\
\hline \multirow{10}{*}{ 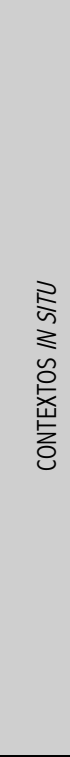 } & 1 & $\begin{array}{l}\text { Losas de la praecinctio } \\
\text { entre proedria e ima } \\
\text { cauea }\end{array}$ & Max.: $120 \times 170$ & Itálica (teatro) / in situ & - & Tardoagustea & $\begin{array}{l}\text { ITA-0238 } \\
\text { (ICAC) }\end{array}$ \\
\hline & 2 & Escalón macizo ima cavea & $77 / 180 \times 37 \times 23$ & Itálica (teatro) / in situ & - & Tardoagustea & - \\
\hline & 3 & Pavimento del aditus & Max.: $116 \times 90$ & Itálica (teatro) / in situ & - & Tardoagustea & - \\
\hline & 4 & $\begin{array}{l}\text { Basamentos de } \\
\text { pedestales en galería } \\
\text { oeste de la } p p s\end{array}$ & $188 \times 90 \times 21$ & $\begin{array}{l}\text { Itálica (teatro) / in situ y } \\
\text { almacén del teatro }\end{array}$ & - & Tardoagustea & $\begin{array}{l}\text { ITA-0253 } \\
\text { (ICAC) }\end{array}$ \\
\hline & 5 & $\begin{array}{l}\text { Fgto. fuste monolítico de } \\
\text { columna en } p p s\end{array}$ & $102 \times 32$ & $\begin{array}{l}\text { Itálica (teatro) / pps } \\
\text { teatro }\end{array}$ & $\begin{array}{l}\text { Rodríguez } \\
2004, \text { FF-70 }\end{array}$ & Indeterminada & $\begin{array}{l}\text { ITA-0237 } \\
\text { (ICAC) }\end{array}$ \\
\hline & 6 & $\begin{array}{l}\text { Fuste/pedestal cilíndrico } \\
\text { epigráfico }\end{array}$ & $36 \times 60$ & $\begin{array}{l}\text { Itálica (teatro) / } \\
\text { almacén del teatro }\end{array}$ & $\begin{array}{l}\text { ERlt 60; CILA } \\
\text { Se 398; } \\
\text { Rodríguez } \\
\text { 2004, FF-60 }\end{array}$ & $\begin{array}{l}\text { Comienzos s. I } \\
\text { d.C. }\end{array}$ & $\begin{array}{l}\text { ITA-0236 } \\
\text { (ICAC) }\end{array}$ \\
\hline & 7 & Losas de pavimento & $\begin{array}{l}\text { Media: } 103 / 148 \times \\
80 / 90 \times 16-22\end{array}$ & $\begin{array}{l}\text { Hispalis (edificio en } \\
\text { Goyeneta 17) / CAl }\end{array}$ & - & S. II d.C. & G-13 (IAPH) \\
\hline & 8 & Losas de pavimento & $\begin{array}{l}29,4 \times 29,4 \times \\
5,9 / 6,3\end{array}$ & $\begin{array}{l}\text { Corduba (forum novum, } \\
\text { Morería, 5) / MAECO }\end{array}$ & $\begin{array}{l}\text { Portillo } 2018, \\
\text { cat. } 58 \text { y } 59\end{array}$ & Tiberiana & - \\
\hline & 9 & Herma epigráfica & $\begin{array}{l}125 \times 28,8-17,5 \times \\
9,7-7,2\end{array}$ & $\begin{array}{l}\text { Astigi (domus área } \\
\text { foro) / MHME }\end{array}$ & - & $\begin{array}{l}\text { Comienzos s. II } \\
\text { d.C. }\end{array}$ & $\begin{array}{l}\text { EM-19 } \\
\text { (IAPH) }\end{array}$ \\
\hline & 10 & $\begin{array}{l}\text { Losas reutilizadas en las } \\
\text { construcciones tardías }\end{array}$ & $36 \times(28) \times(15)$ & $\begin{array}{l}\text { Astigi (área del antiguo } \\
\text { foro colonial, Plaza de } \\
\text { España) / MHME }\end{array}$ & - & $\begin{array}{l}\text { Reutilizadas en } \\
\text { época } \\
\text { tardoantigua }\end{array}$ & - \\
\hline \multirow{4}{*}{ 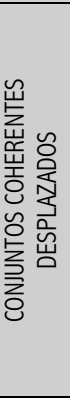 } & 11 & Losas de pavimento & $\begin{array}{l}115 / 130 \times 57 / 60 \times \\
20\end{array}$ & $\begin{array}{l}\text { Peñaflor / Jardín ermita } \\
\text { de Nuestra Señora de } \\
\text { Villadiego }\end{array}$ & - & $\begin{array}{l}\text { Romana } \\
\text { indeterminada }\end{array}$ & - \\
\hline & 12 & Basa ática & $\begin{array}{l}72 \text { (diám. sup.), } 80 \\
\text { (lado plinto) }\end{array}$ & $\begin{array}{l}\text { Peñaflor / Jardín ermita } \\
\text { de Nuestra Señora de } \\
\text { Villadiego }\end{array}$ & - & $\begin{array}{l}\text { Altoimperial } \\
\text { indeterminada }\end{array}$ & - \\
\hline & 13 & $\begin{array}{l}\text { Losa con inscripción } \\
\text { funeraria (Fabia Merope) }\end{array}$ & $86 \times 27 \times 4 / 5$ & $\begin{array}{l}\text { Peñaflor / Interior } \\
\text { ermita de Nuestra } \\
\text { Señora de Villadiego }\end{array}$ & $\begin{array}{l}\text { AE } 1975,503 \\
\text { AE } 1976,281 \\
\text { CILA Se } 175 \\
\end{array}$ & $\begin{array}{l}\text { Reutilizada en } \\
\text { la } 2^{\mathrm{a}} 1 / 2 \text { del s. } \| \\
\text { d.C. }\end{array}$ & - \\
\hline & 14 & $\begin{array}{l}\text { Fustes de columna } \\
\text { reutilizados }\end{array}$ & $336 \times 42 / 47$ & $\begin{array}{l}\text { Córdoba / Interior de la } \\
\text { Mezquita }\end{array}$ & $\begin{array}{l}\text { Peña } 2010, \\
\text { cat. } 71,86 \text { y } \\
189\end{array}$ & $\begin{array}{l}\text { Altoimperial } \\
\text { indeterminada }\end{array}$ & - \\
\hline \multirow{4}{*}{ 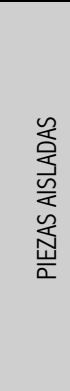 } & 15 & $\begin{array}{l}\text { Pedestal cilíndrico } \\
\text { epigráfico (Augusto } \\
\text { Sacro) }\end{array}$ & $102 \times 41 / 47$ & $\begin{array}{l}\text { Córdoba (Hospital de } \\
\text { La Lámpara) / MAM } \\
\text { (colección Loring- } \\
\text { Villacevallos) }\end{array}$ & $\begin{array}{l}\text { CIL II 2197; CIL } \\
\text { II2/7 253 } \\
\text { Garriguet } \\
\text { 2002, cat. 1b }\end{array}$ & Tardoagustea & - \\
\hline & 16 & $\begin{array}{l}\text { Pedestal cilíndrico } \\
\text { epigráfico (Dasumia } \\
\text { Turpilla) } \\
\end{array}$ & $119 \times 48$ & $\begin{array}{l}\text { Alcalá del Río / Interior } \\
\text { ermita de San Gregorio } \\
\text { Ossetano }\end{array}$ & $\begin{array}{l}\text { CIL II 1089, } \\
\text { supl. P. } 837 \\
\text { CILA Se } 297 \\
\end{array}$ & S. I d.C. & - \\
\hline & 17 & Losa de pavimento & $275 \times 145 \times 24$ & $\begin{array}{l}\text { Écija / Atrio de la iglesia } \\
\text { de Santa María }\end{array}$ & - & Indeterminada & - \\
\hline & 18 & Miliario & $86 \times 26$ & La Luisiana / MAPS & $\begin{array}{l}\text { HEp 1994, } \\
\text { 769; HEp } \\
\text { 1995, } 723\end{array}$ & & - \\
\hline
\end{tabular}

Figura 7: Tabla-resumen de los contextos y/o piezas objeto de estudio

al cual se distribuían. Las placas que corresponden a las interrupciones que hicieron las veces de puertas en el balteus fueron cortadas en sus laterales de forma oblicua a fin de dejar el espacio para el encaje de las losas verticales y, a su vez, alcanzar tangencialmente en su frente las losas de mármol blanco de la proedria. Ello las identifica como propias de una misma planificación con el conjunto de los acabados marmóreos del sector, en variedades blancas de Almadén de La Plata y Mijas. Destaca la perfección en el encaje entre sí de las diferentes losas, así como en la cota horizontal lograda en todo el pasillo. En el mismo material se ejecutó un primer escalón (Rodríguez Gutiérrez, 2004: 80; 2008: 237, tabla 1,251) (n. ${ }^{\circ}$ ), a modo de escabel, de $37 \mathrm{~cm}$ de tabica por 23 de huella, a partir del cual ya los gradus continuaron en piedra alberiza, aunque con aplacados marmóreos en la ima cavea. De nuevo estos bloques son de dimensiones diferentes; las longitudes oscilan entre 77 y $180 \mathrm{~cm}$. En su frente ofrecen una muy ligera curvatura para adaptarse a la forma semicircular de la cavea. Dicha precisión lleva a pensar, sin duda, que los ajustes y desbastados finales se llevaran a cabo en obra o en un taller asociado directamente a ella.

Sin duda esta piedra poseía un valioso equilibrio entre dureza y vistosidad, de la que carecían otros materiales idóneos para estos usos, como la conocida losa de Tarifa o la piedra de mina ${ }^{3}$. Por ello también se empleó en los pavimentos del aditus hasta llegar a la misma

3. Caliza micrítica extraída en el entorno directo de la ciudad de Corduba, con evidencia de explotación antigua en el paraje 


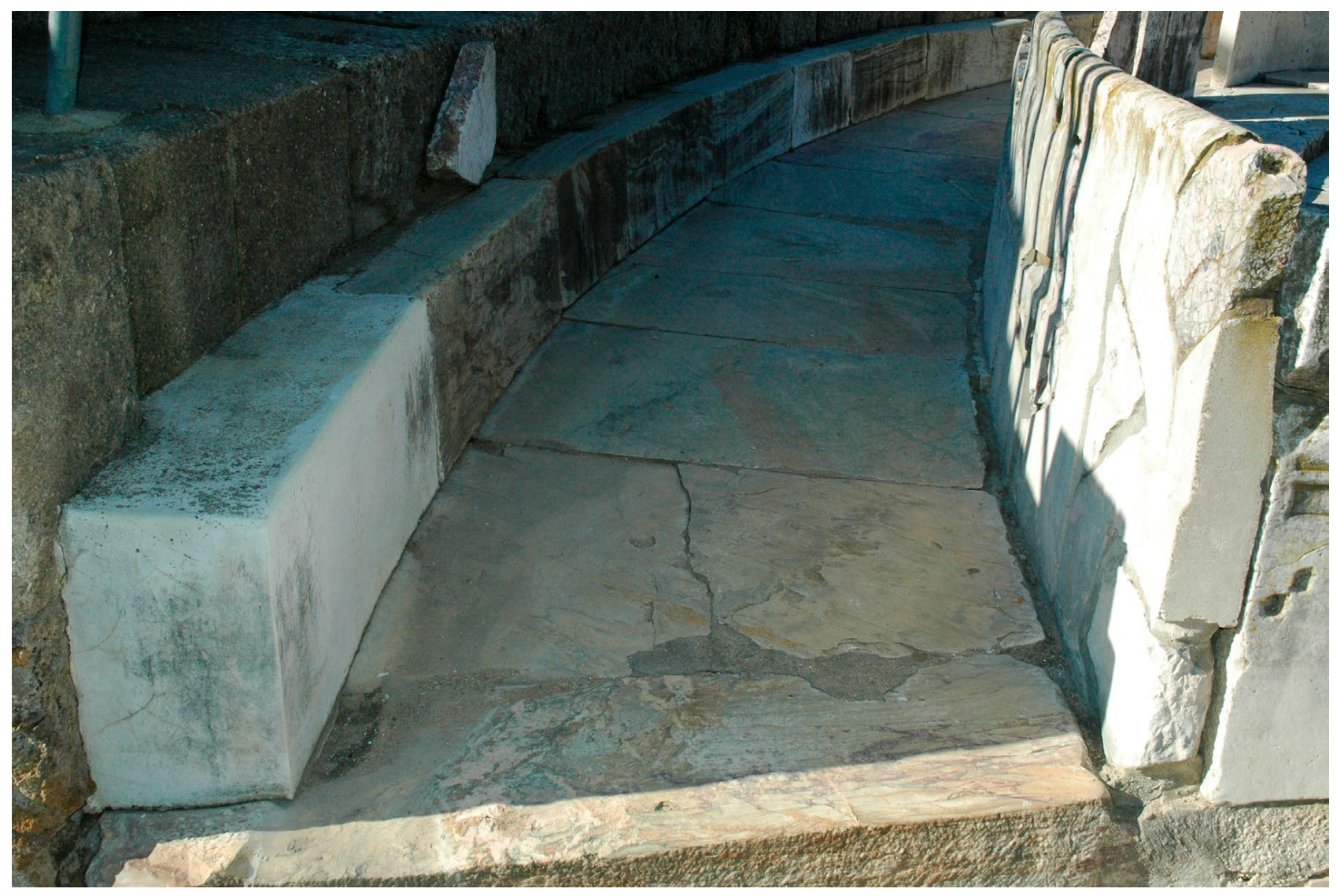

Figura 8: Pavimento de la praecinctio entre el balteus de la orchestra y la ima cavea y del primer escalón de transición con esta última, del teatro romano de Itálica.

$\operatorname{orchestra}\left(\mathrm{n}^{\mathrm{o}}\right.$ 3), un sector del edificio de importante monumentalidad y simbolismo. De forma diferencial se han conservado testimonios in situ en ambos itinera, en forma de grandes losas con dimensiones y despieces diferentes ${ }^{4}$.

También esta variedad polícroma fue la elegida para ejecutar los basamentos (y quizá también los coronamientos, hoy perdidos) de una serie de pedestales ecuestres colocados en los intercolumnios de la galería oeste de la porticus post scaenam (n. ${ }^{\circ} 4$, Fig. 9). Hallados in situ en el curso de la excavación del sector en la campaña de 1975, se conservan tres de ellos. Sus dimensiones son 188 × $90 \times 21 \mathrm{~cm}$. Soportaban dados de pedestal destinados a estatuas ecuestres de tamaño menor que el natural. Solo uno de ellos se ha conservado, con la dedicación de una mujer, Amoena, a su padre Lucio Pontio (ERit 61, CILA Se 399). Fue realizado en mármol de Alconera, de conocidas tonalidades violáceas. Al grupo cabe sumar otros dos fragmentos de la serie, depositados en el almacén del teatro.

conocido como Rodadero de los Lobos (Gutiérrez Deza, 2012: 302-304).

4. Solo las losas conservadas en el iter norte cubren una superficie total de $5 \mathrm{~m}^{2}(203 \times 246 \mathrm{~cm})$, si bien habría que pensar en una más que probable extensión a lo largo del pasillo, al menos, hasta llegar a la orchestra, como se ha documentado en el lado opuesto.
El conjunto de este edificio italicense se completa con dos singulares piezas más, procedentes de las excavaciones en el mismo pero con menor información sobre su contexto original de uso. Un fragmento inferior con moldura de imoscapo de fuste monolítico liso, de $102 \mathrm{~cm}$ de longitud máxima conservada y 32 $\mathrm{cm}$ de diámetro (Rodríguez Gutiérrez, 2004: cat. FF-70; 2008: 237, tabla 1, 251) (n. ${ }^{\circ} 5$, Fig. 10). El módulo no se ajusta a ninguno de los órdenes identificados hasta el momento en el edificio si bien sus pequeñas dimensiones podrían permitir adscribirlo a decoración menor del frente escénico. Una última pieza, actualmente en el almacén del teatro pero, al parecer, hallada en uno de los laterales de la escena, corresponde a un fragmento de posible fuste cilíndrico liso de pedestal, de $36 \mathrm{~cm}$ de altura y 60 de diámetro. Presenta una inscripción distribuida en dos líneas: [---]a.t(iti).f(ilia).[---]/[---] soror, en letra capital cuadrada de buena factura. Se data en época altoimperial indeterminada ${ }^{5}$.

5. ERIt 60; CILA Se 398; Rodríguez Gutiérrez, 2004: n. ${ }^{\circ}$ cat. FF-60 e I.68; 2008: 237, tabla 1, 253, n. ${ }^{\circ}$ 58. En CILA se propone una datación del siglo II d. C., si bien los criterios paleográficos -con claras similitudes con otras inscripciones del edificio como la losa de Lucio Herio (CILA Se 382)-, parecen indicar fechas mucho más tempranas de, al menos, comienzos del siglo I d. C. Agradecemos aquí al profesor S. Ordóñez sus amables indicaciones al respecto. 


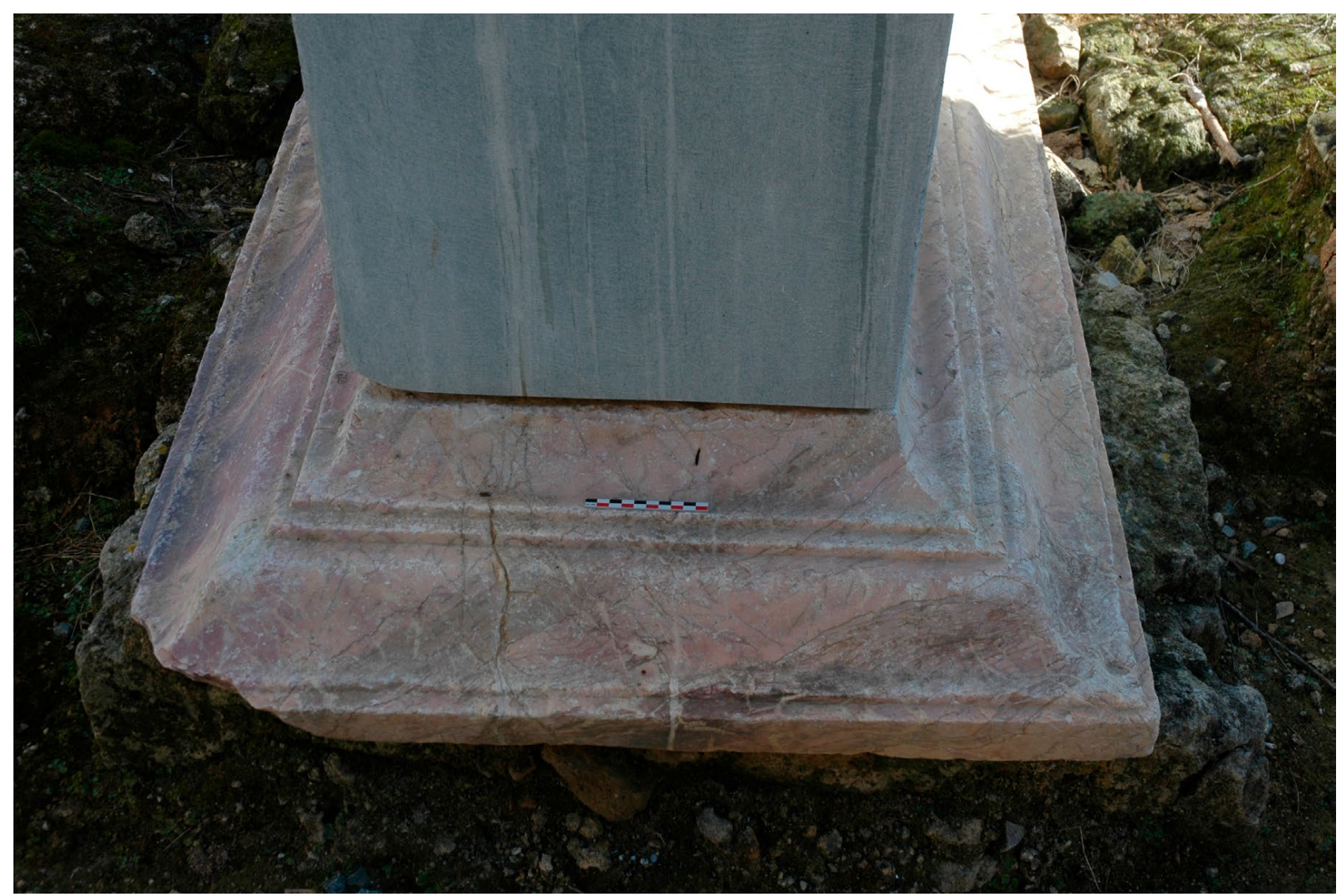

Figura 9: Basamento de pedestal de estatua ecuestre de la galería oeste de la porticus post scaenam del teatro de Itálica

Tanto los bloques de la praecinctio como los pedestales de la galería occidental de la porticus post scaenam pueden ser claramente adscritos a la construcción del edificio, a partir de las relaciones estratigráficas relativas que se establecen entre los diferentes elementos constructivos. A ello se suman otros indicios, como pueda ser el epígrafe del dado de pedestal de Lucius Pontius, datado asimismo en este momento por criterios paleográficos. No deja de ser de gran interés, en estos contextos, la combinación, en estas fechas medio-tardo augusteas, de la variedad polícroma con otras locales de gran relevancia y difusión en la provincia, como las blancas de Mijas y Almadén de La Plata (balteus, proedria) y Alconera (pedestal de Pontio).

\subsubsection{Edificio excavado en la calle Goyeneta $17, \mathrm{Se}-$ villa}

El conjunto material procede de un edificio excavado tan solo parcialmente, entre 2008 y 2009, en un solar del actual centro histórico de la ciudad de Sevilla. Se encontraba intramuros, muy próximo tanto al que se supone fue el antiguo curso del río Baetis (Borja Barrera, 2018), como al barrio portuario documentado bajo la Plaza de La Encarnación (González Acuña, 2011; Beltrán y Rodríguez Gutiérrez, 2018: 176-178). El mármol polícromo que nos ocupa se empleó en la segunda de las fases constructivas, datada en un momento impreciso del siglo II d. C. y con perduración hasta la cuarta centuria. Lamentablemente, las vicisitudes de la excavación y su limitada superficie impidieron caracterizar la planta del conjunto en una extensión suficiente que permitiese avanzar en su interpretación funcional. No obstante, se reconoce un edificio de considerable monumentalidad, tanto en lo que se refiere a dimensiones como a acabados, organizado en torno a un patio abierto ${ }^{6}$ con una galería porticada de la que se conservan los apoyos de las pilastras adosadas a la pared de fondo, en mármol lunense. También son significativos, al menos, dos fustes lisos de $62 \mathrm{~cm}$ de diámetro en una suerte de travertino amarillento ${ }^{7}$.

La piedra coloreada se empleó en el pavimento del patio, en forma de grandes losas de forma prismática, algunas de ellas halladas in situ (Fig. 11), otras ya en posición secundaria (n. $\left.{ }^{\circ} 7\right)$. El acabado de los planos de apoyo es muy tosco e irregular, en una suerte de anathyrosis, confirmada por la presencia de mortero de cal adherida en algunas piezas. Actualmente se

6. De al menos $15 \mathrm{~m}$ de anchura, incluida la galería porticada perimetral.

7. La excavación permanece inédita aunque un trabajo sobre el uso del mármol en los diferentes elementos recuperados se presentó al XI Congreso de la Asmosia celebrado en Split en 2016: Taylor et al., 2018. La variedad polícroma corresponde al número 6 de la clasificación incluida en dicho trabajo. 


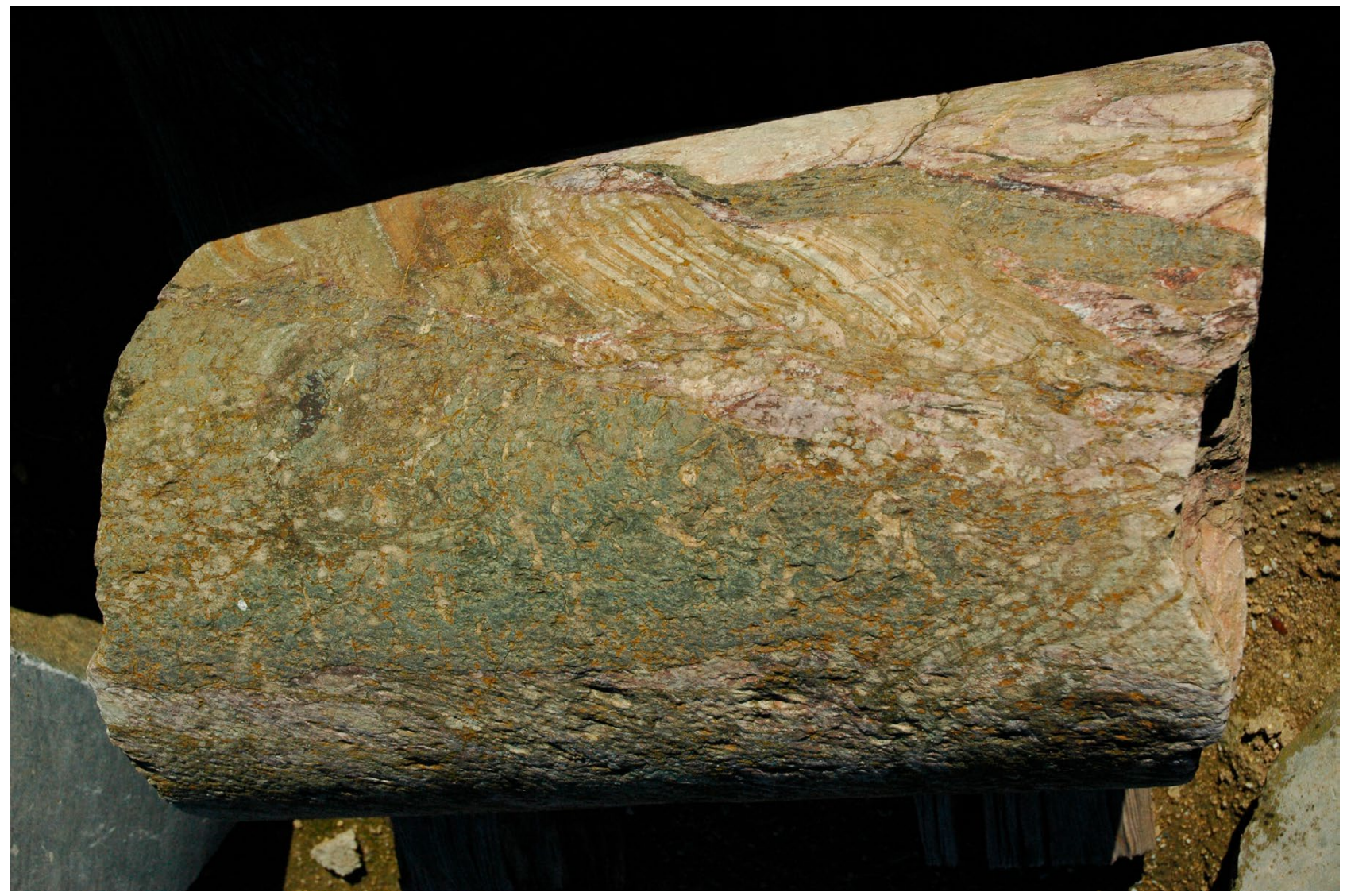

Figura 10: Fragmento de fuste monolítico hallado en las excavaciones en el teatro de Itálica

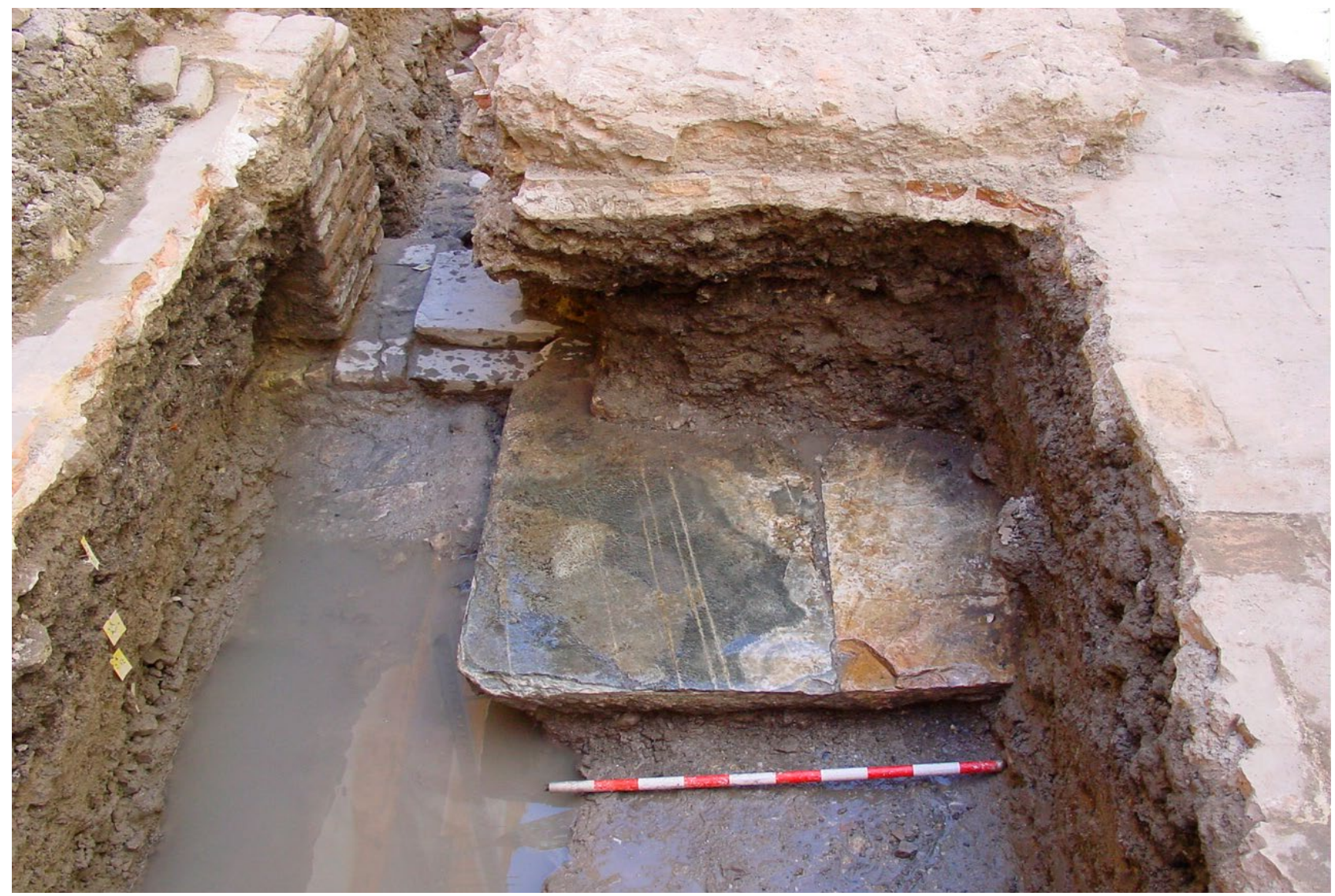

Figura 11: Vista de las losas de pavimento in situ excavadas en el curso de la IAP realizada en el n. ${ }^{\circ} 17$ de la calle Goyeneta, en Sevilla 
conservan $^{8}$ once losas completas de dimensiones bastante heterogéneas especialmente en longitud (103-148 $\mathrm{cm})$, más regulares en anchura $(80-90 \mathrm{~cm})$ y espesor $(16-22 \mathrm{~cm})$. Dos de ellas presentan despieces oblicuos, lo que hace pensar en un complejo juego de engaste entre bloques, al modo del documentado en el ya descrito pasillo de la orchestra del teatro italicense. Una última también presenta el frente con una molduración lisa sencilla: un cuarto de bocel y un toro en lo conservado.

En el conjunto de materiales arquitectónicos (Taylor et al., 2018), aunque de no todos ellos se pueda garantizar un funcionamiento coetáneo, se reconoce, por tanto, la combinación de piedras locales con otras foráneas. Al mármol lunense (basas de pilastra) se unen diferentes variedades de Almadén de La Plata (basamentos, basas y fustes de columna), caliza oolítica rosada de Sintra (fustes de columna), así como el citado travertino bandeado en grandes fustes monolíticos de columna y cuyo origen podría ser norteafricano (act. Argelia), aunque no se descarta la procedencia local (Loza y Beltrán, 2018). También la denominada losa de Tarifa se documenta en bloques de pavimento muy semejantes a los descritos para la piedra polícroma, haciendo pensar en la posible combinación de ambos simultáneamente, quizá de acuerdo a algún patrón que desconocemos. De nuevo, el mármol polícromo forma parte aquí de una selección consciente $\mathrm{y}$ con variedades de considerable coste y prestigio.

\subsubsection{Forum novum de Corduba}

Un tercer conjunto de piezas documentadas en directa relación con su lugar original de ubicación corresponde al denominado forum novum de Colonia Patricia (Corduba) (Portillo, 2018), también conocido en la bibliografía como el recinto de la calle Morería. Es del máximo interés por diferentes razones: la primera, por su identificación como un espacio dedicado al culto imperial (concretamente a Augusto divinizado) en la capital provincial; la segunda, su datación a comienzos de tiempos julio-claudios. En todos los casos las piezas corresponden a losas pavimentales, completas y fragmentadas, procedentes del solar $\mathrm{n}$. 5 de la calle Morería (Gutiérrez Deza, 2007: 102, 43) (n. ${ }^{\circ}$ 8). Dos de ellas ${ }^{9}$ se encuentran completas, de dimensiones 29,4 x 29,4 x 5,9/6,3 cm. El conjunto recuperado se ha atribuido al enlosado de la cella del templo, aunque tampoco se descarta su adscripción a la plaza del foro (Portillo, 2018: 55-56, 96-97). En esta última se ha identificado, con certeza, el empleo de losas de caliza micrítica gris, ya

8. Los grandes elementos arquitectónicos procedentes de esta intervención se encuentran, en depósito temporal, en el Conjunto Arqueológico de Itálica.

9. Corresponden a los números 58 y 59 del catálogo de Portillo 2018, incluidos en el grupo cuatro, «de adscripción segura al interior del templo». citada, conocida como «piedra de mina», no pudiendo afirmarse si ambos materiales aparecerían combinados en el mismo suelo o si, más probablemente, responderían a una más marcada jerarquización funcional. En este contexto nuevamente a las variedades locales de marmora, entre las que destacan las de Almadén y Estremoz, se unen otras foráneas, especialmente la frecuente trilogía compuesta por el giallo antico, el cipollino y el pavonazzetto, en su mayor parte en forma de lastras tanto pavimentales como parientales, así como formando parte de pequeños órdenes decorativos.

A su vez, es preciso también tener en cuenta un grupo de placas en este mismo material y muy similares en formato a las anteriores, ahora reempleadas en el pavimento en la puerta de los Deanes de la Mezquita de Córdoba. Parece probable que procedieran igualmente del conjunto del forum novum (Portillo, 2018: 96-97), siendo reutilizadas una vez que fue abandonado.

\subsubsection{Materiales del foro de Astigi y su entorno}

Dos piezas in situ han sido documentadas en el curso de las excavaciones arqueológicas llevadas a cabo en torno al año 2005 en la conocida como Plaza de España de la Écija actual. Se encuentran en diferentes contextos funcionales, lo que las hace aún más interesantes en lo que se refiere a la diversificación de la producción. La más singular, sin duda, es una herma hallada en el ángulo suroccidental del peristilo de la domus excavada en el sector meridional de la insula oeste del conjunto, caída directamente sobre el pavimento del pórtico, en el área suroccidental del peristilo (García-Dils et al., 2006: 354) (n. ${ }^{\circ}$ 9, Fig. 12). Es de forma ligeramente troncopiramidal invertida, de dimensiones 125 x 28,817,5 x 9,7-7,2 cm. Está completa y en excelente estado de conservación, con un pulimento de gran calidad en el plano frontal ${ }^{10}$. Es aquí donde presenta un inscripción distribuida en cinco líneas: Q(uinto) Auilio / Q(uinti) f(ilio) Pap(iria tribu) $\beta$ Valeriano / Megale / lib(erta) ded(it). En la pieza parece haberse tratado de sacar partido ornamental a las vetas naturales de la piedra que, en este caso, presenta una gran variabilidad de tonalidades, destacando los amarillentos, rosados, morados y verdosos. Se ha datado en tiempos adrianeos por criterios paleográficos. No obstante, tanto el lugar como el contexto de hallazgo sugieren que se hubiera mantenido en uso e in situ hasta la amortización definitiva de la vivienda, avanzada la época tardoantigua.

Formó parte de un conjunto de al menos tres piezas, todas ellas hermae dedicadas por una liberta a tres miembros de una misma familia (abuelo-padre-hijo o padre-hijo-sobrino), dentro, por tanto, de un programa decorativo y dedicatorio único. De ellas, las otras dos se realizaron en una brecha de matriz calcárea y

10. Una muy detallada y precisa descripción de la pieza en García-Dils et al., 2006: 356. 


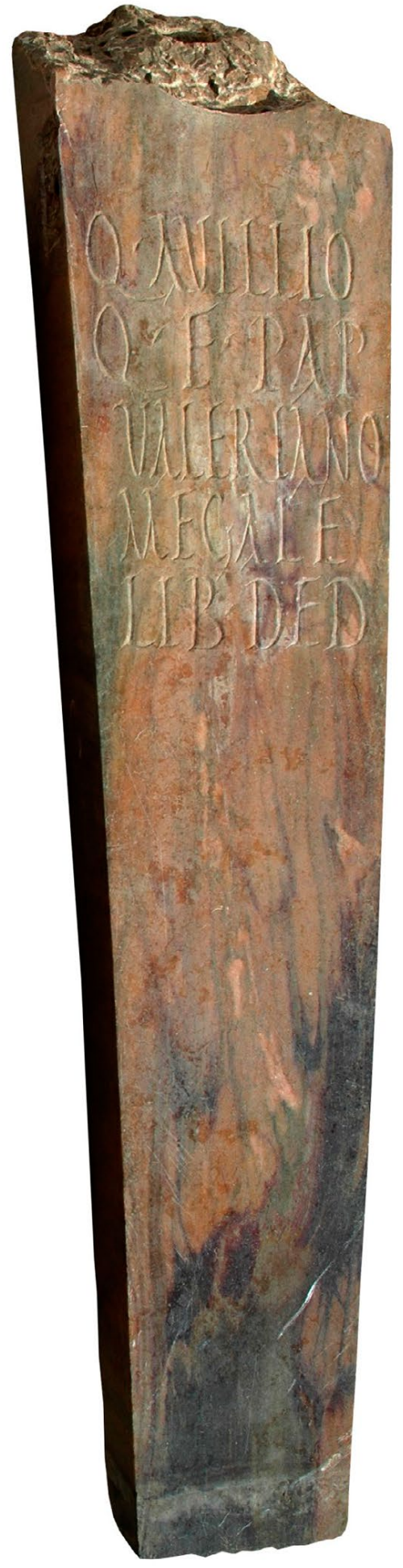

Figura 12: Herma hallada en contextos domésticos romanos en la Plaza de España de Écija

fueron ya amortizadas con motivo de una contundente reforma de la vivienda fines del siglo IV, comienzos del V d. C. (García-Dils et al., 2006: 353). Fue quizá la belleza del material de soporte la que habría propiciado el mantenimiento de la que nos ocupa, a pesar de la transformación de la vivienda. A pesar del diferente material, los criterios paleográficos de las inscripciones han planteado que las tres se hubieran realizado en un mismo taller e, incluso, a cargo de un mismo artífice (García-Dils et al., 2006: 363).

Losas del mismo material polícromo se documentaron reutilizadas en el área del antiguo foro de la colonia, bajo la actual Plaza de España (n. $\left.{ }^{\circ} 10\right)$. Por su morfología parecen tratarse de lastras pavimentales que, en un segundo momento, se reutilizaron como revestimiento parietal, quizá zócalo en la base de los muros, con motivo de la reformas de las antiguas construcciones públicas ya en época tardía. Al igual que ocurre con la herma ya descrita, este vistoso material parece haber sido valorado a lo largo del tiempo, propiciando su mantenimiento y/o reutilización aún en tiempos tardoantiguos. En el tercer grupo de nuestra clasificación se incluye asimismo una última pieza astigitana, si bien reutilizada en una iglesia $\mathrm{y}$, por ello, sin vínculos contextuales de procedencia y/o uso.

\subsection{SEgundo GRUPO: CONJUNTOS COHERENTES DES- PLAZADOS}

4.2.1. Materiales de la ermita de Nuestra Señora de Villadiego de Peñaflor ${ }^{11}$

En la actual ermita de Nuestra Señora de Villadiego, situada a las afueras de la localidad de Peñaflor, antigua Celti, se conserva un numeroso conjunto de piezas, en su mayoría realizadas en la piedra polícroma objeto de este estudio. El propio umbral de acceso al templo está realizado en este material. Parecen haberse ido acumulando allí a lo largo del tiempo, sin que se conozca con certeza el lugar de origen ni se tengan totales garantías, en todos los casos, de su datación antigua.

Buena parte de ellas son grandes losas paralelepipédicas (n. ${ }^{\circ} 11$, Fig. 13), con uno de sus planos horizontes bien acabado y pulido; el resto muestra un trabajo diferencial de la piedra, desbastado toscamente en muchos casos. Sus dimensiones medias son, aproximadamente, $115 / 130$ x 57/60 cm y $20 \mathrm{~cm}$ de grosor. Dos de ellas presentan cavidades de forma circular y sección cóncava para el alojamiento y giro de goznes de puerta que, pudiendo ser originales, también podrían deberse a reutilizaciones posteriores. Son, por tanto, muy semejantes en morfología y dimensiones a las losas de pavimento documentadas tanto en el aditus del teatro italicense como, especialmente, en la excavación urbana de la sevillana

11. Se ha documentado igualmente en este material, también descontextualizada y reutilizada en uno de los ángulos de la actual iglesia parroquial de la localidad, una basa con alto plinto sobre la que se apoya un fragmento de sección mucho menor de fuste torso de mármol grisáceo. No obstante, su tipología no parece claramente romana, pudiendo ser muy posterior. Existen también noticias de otras piezas de este material (ref. F. Amores Carredano), a juzgar por las descripciones orales, en diferentes colecciones privadas de Peñaflor, de donde la variedad, como ya hemos indicado, adquirió su primera denominación. 


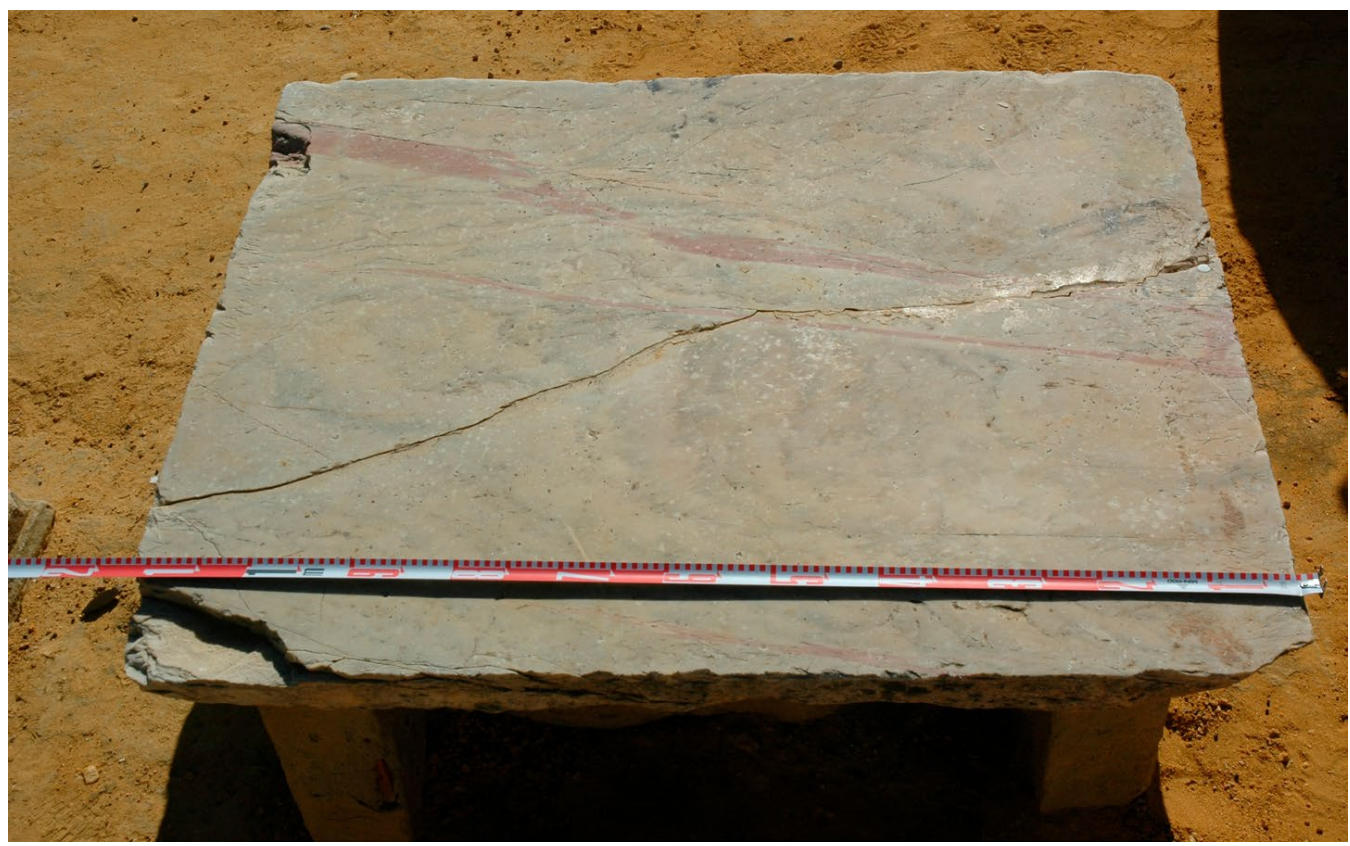

Figura 13: Bloque paralelepipédico (lastra pavimental) conservado en la ermita de Nuestra Señora de Villadiego de Peñaflor

calle Goyeneta, lo que lleva a confirmar esta función también para ellas y su muy probable cronología romana.

En el conjunto cabe además individualizar una basa ática (n. $\left.{ }^{\circ} 12\right)$ de tipología canónica de $72 \mathrm{~cm}$ de diámetro el toro superior y $80 \mathrm{~cm}$ de lado del plinto y una lastra fragmentada (n. ${ }^{\circ} 13$, Fig. 14). Esta última fue reutilizada como epígrafe sepulcral, tal y como demuestra el irregular perímetro del lateral derecho al que se adapta la inscripción, de doce líneas: $D$ (is) $M$ (anibus) S(acrum) / Atimeti lib(erta) $\beta$ Fabia Mer / ope anno / rum LXXV/6 pia in suis / h(ic) s(ita) e(st) s(it) t(ibi) t(erra) l(evis) / si quantum pietas potu $/ 9$ it tantum fortuna / dedisset litteris au / ratis scribere $<m>$ hunc $/ 12$ titulum (Chic, 1975: 359-361; AE 1975, 503; CILA Se 175). Fue hallada en los años setenta del siglo pasado con motivo de unas excavaciones en el casco urbano de Peñaflor junto, al menos, a otra también funeraria. Se ha datado, por criterios paleográficos, en la segunda mitad del siglo II d. C. (Chic, 1975: 360).

\subsubsection{Fustes de la mezquita de Córdoba}

Son tres fustes monolíticos de columna (n. ${ }^{\circ}$ 14, Fig. 15), con remates moldurados en imoscapo y sumoscapo. Las dimensiones son $336 \mathrm{~cm}$ de altura por $42 / 47 \mathrm{~cm}$ de diámetro (Peña 2010, 127-128, cat. n. ${ }^{\text {os }} 71,86$ y 189).

Las piezas forman parte del conjunto de spolia incorporados en las reformas de la mezquita, aparentemente, en diferentes momentos: desde el edificio primitivo hasta las obras llevadas a cabo para su transformación en catedral cristiana. En los estudios específicos sobre los elementos arquitectónicos reutilizados en el edificio (Peña, 2009: 256, fig. 8 en p. 257; 2010: 128) se han incluido entre los materiales de las canteras lusitanas de Estremoz, a las que también se adscribe otros ejemplares bandeados en blanco/gris. Es importante hacer notar que, en los últimos años, desde la publicación de estas relevantes investigaciones, se ha avanzado notablemente en la problemática discriminación entre estas variedades lusitanas y las béticas de Almadén de La Plata (Lapuente et al., 2014: 334), en cuya revisión, además, convendría incluir los fustes que aquí nos ocupan, como una tercera variedad independiente de las anteriores.

Procederían de un edificio de la Corduba altoimperial. Por sus dimensiones, sería muy probablemente público o, al menos, de cierta monumentalidad.

\subsection{TERCER GRUPO: PIEZAS AISLADAS}

4.3.1. Pedestal cilíndrico de Corduba (colección Villacevallos) (n. ${ }^{\circ}$ 15, Fig. 16)

En la actualidad se encuentra en el Museo Arqueológico de Málaga, si bien ello se debe a las vicisitudes seguidas por la colección de Pedro Leonardo de Villacevallos (s. XVIII), de la que formaba parte. Según J.A. Garriguet (2002: 62) quien, a su vez, se basa en el testimonio de B. Sánchez de Feria de 1772, se halló en el antiguo Hospital de la Lámpara, situado en la calle Amparo, junto al ángulo SE de la antigua muralla romana de la ciudad de Córdoba. Á. Ventura ha planteado que procediera originalmente del teatro (Ventura, 1996: 164; 1999: 65; 2002: 123-124).

Es una columna-pedestal ${ }^{12}$, monolítica y de sección cilíndrica, de $102 \mathrm{~cm}$ de altura y 41-47 cm de diámetro

12. El interés de la pieza ha generado abundante bibliografía: Ventura, 1999: 64-65, n. ${ }^{\circ} 1$, fig. 9; 2002: 123-124; Garriguet, 


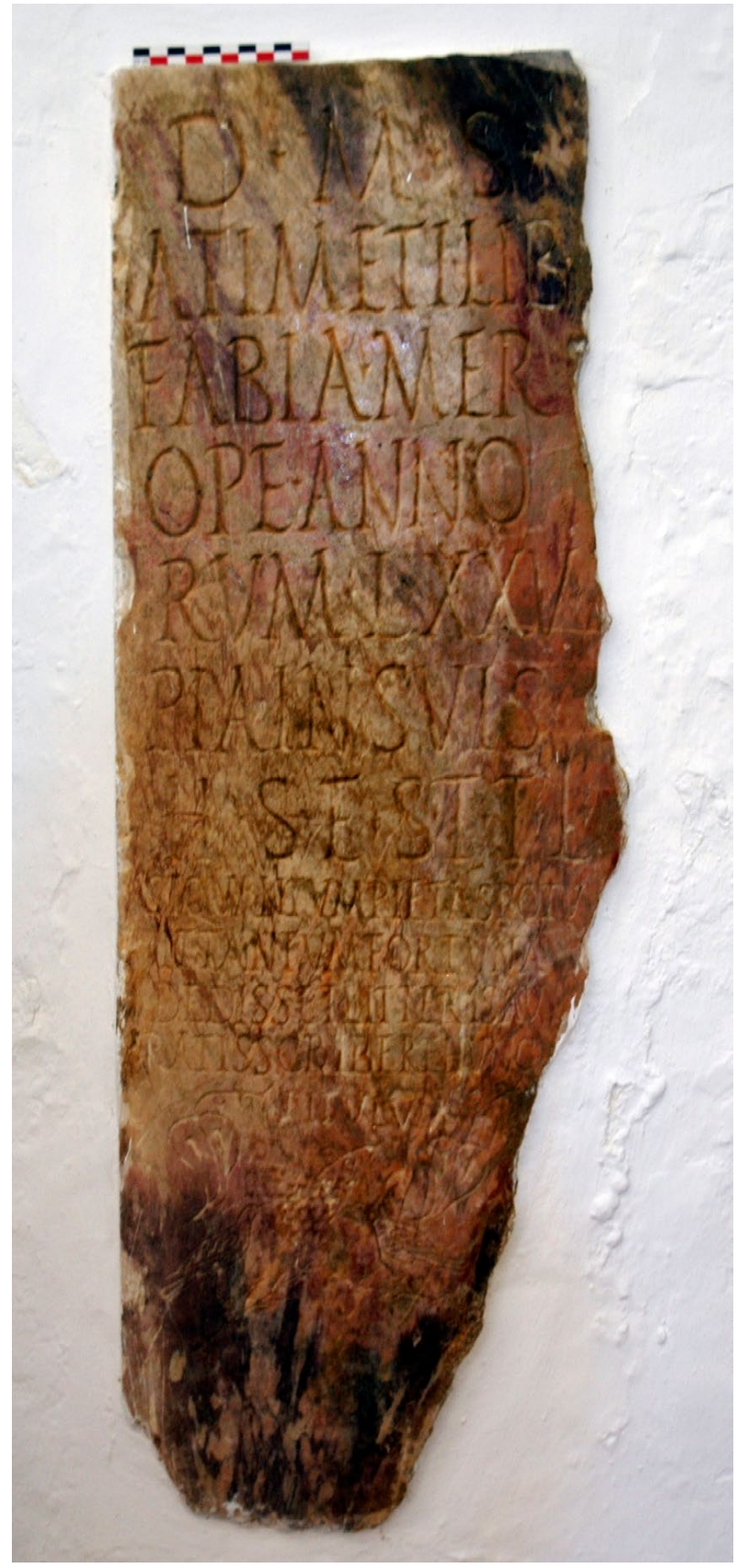

Figura 14: Epígrafe funerario conservado en la ermita de Nuestra Señora de Villadiego de Peñaflor

(Garriguet, 2002: 61; Ventura, 2002: 123). Conserva la moldura inferior, formada por un grueso toro inferior y un caveto, así como algunos sectores de la superior, aparentemente otro toro en resalte. Presenta la inscripción Augusto Sacrum en dos líneas (CIL II 2197; CIL II2/7 253). Para la localización del campo epigráfico parece haberse jugado, intencionadamente, con las vetas de la

2002: cat. n. ${ }^{\circ}$ 1b, 61-62; López Rodríguez, 2003: 105; Beltrán, 2003: 131; Gimeno y Stylow, 2003: 164; Beltrán, 2004: 110, n. 28; Rodríguez Gutiérrez, 2008: 251, n. 55; 253, n. 58; Caballos, 2016: 195-196, lám. I.

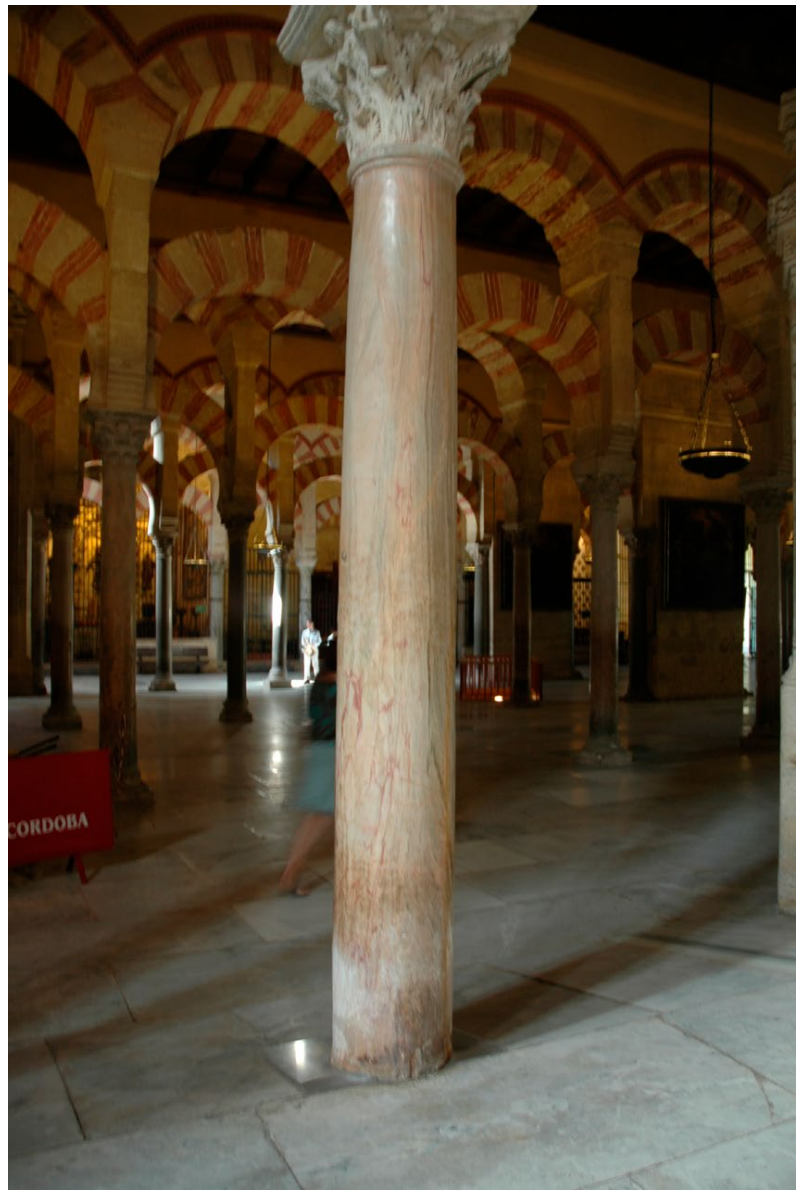

Figura 15: Fuste monolítico de columna reutilizado en la mezquita de Córdoba

piedra, que forman a modo de una guirnalda bajo las dos líneas de la inscripción (Ventura, 2002: 123). J.A. Garriguet (2002: 61), que propone para ella una datación tardoaugustea, se decanta por el valor sacro de la pieza, resaltando el interés de un eventual culto en la capital al emperador incluso ya en vida; otros autores como D. Fishwick (1991: 442-445 en Garriguet, 2002: 62) parecen ver en ese tipo de fórmulas un sentido más honorífico que religioso. En cualquier caso, a efectos del presente estudio, para nosotros es suficientemente interesante que se haya elegido este material para una dedicación en uno u otro sentido.

4.3.2. Pedestal cilíndrico de Ilipa (ermita de San Gre-

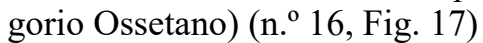

De procedencia imprecisa, las primeras noticias sobre la pieza son ya de la primera mitad del siglo XVIII (ref. M. García Merchante), momento en el que ya se encontraba en la ermita - urbana $^{13}$ - de San Gregorio

13. En HEp 4, 1994, 697 A. Canto atribuye la pieza a Itálica, al partir de la consideración errónea del carácter suburbano de la citada ermita. 


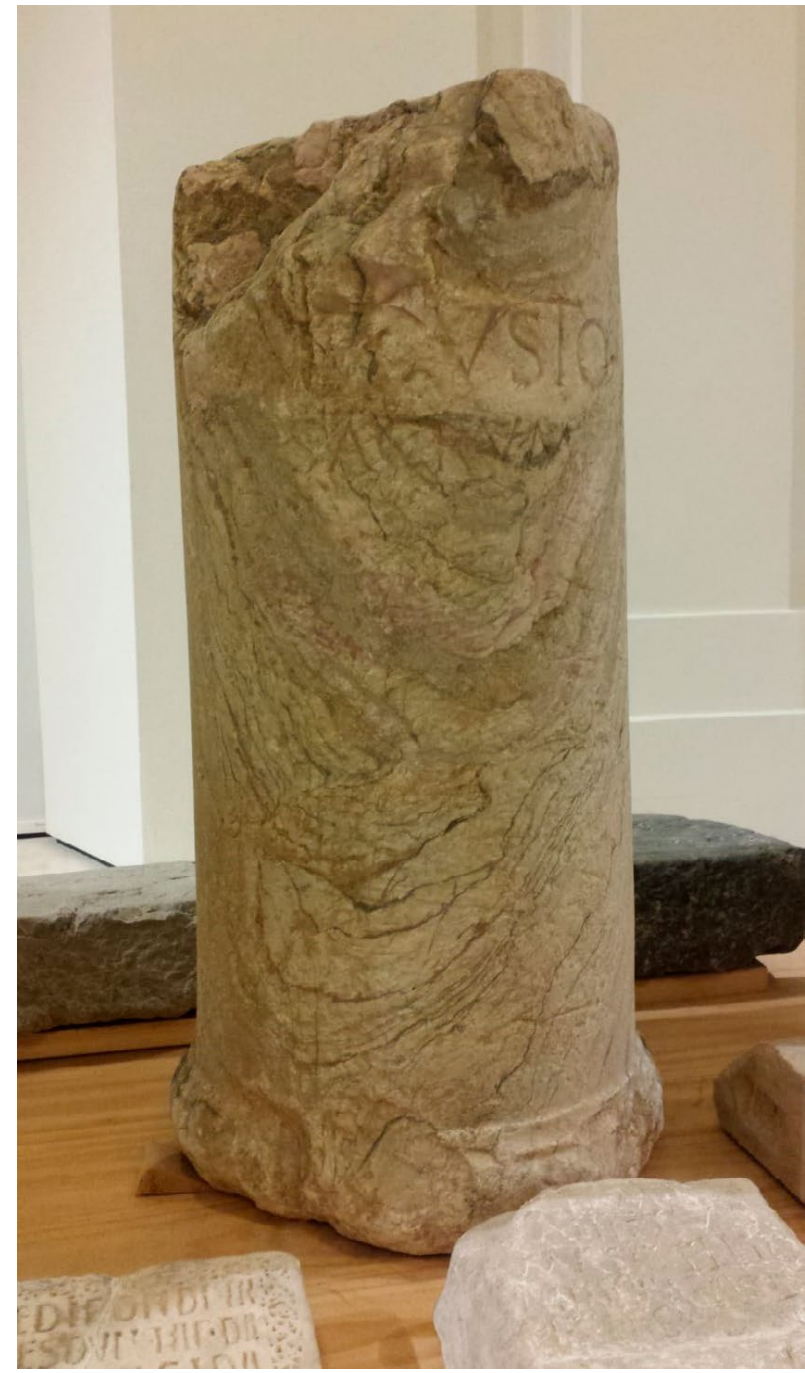

Figura 16: Pedestal cilíndrico epigráfico de la colección Villaceballos, procedente de Córdoba. Actualmente en el Museo Arqueológico de Málaga (Fotografía: J.M. Sánchez Vázquez)

Ossetano de Alcalá del Río. Es un pedestal cilíndrico de $119 \mathrm{~cm}$ de altura por 48 de diámetro (Rodríguez Gutiérrez et al., 2007: 227, n. 6; 240, n. 50; Rodríguez Gutiérrez, 2008: 253, n. 58), reconvertido en pila bautismal. La inscripción (CIL II 1089, supl. p. 837; CILA Se 297), en letra capital cuadrada de cierta calidad, se encuentra distribuida en seis líneas: Dasumia L(ucii) f(iliae) / Turpillae popul(us) $\beta$ laudation(em) public(am) / inpemsam funer(is) / locum sepultur(ae) ${ }^{16} d$ (ecreto) d(ecurionum). Ello permite reconocerlo como un pedestal honorífico que plasma una disposición municipal por la que se concede honras fúnebres a una mujer (Navarro, 2017: n. cat. 112, 440). La paleografía parece apuntar a un momento bastante inicial de la época imperial, con letras «P» sin cerrar y «O» muy esféricas; ello es reforzado por la inexistencia de campo epigráfico delimitado (Navarro, 2017: 440) ${ }^{14}$. Cabe

14. No obstante, hay estudios que se llevan la pieza, a nuestro juicio sin demasiada justificación, desde época republicana

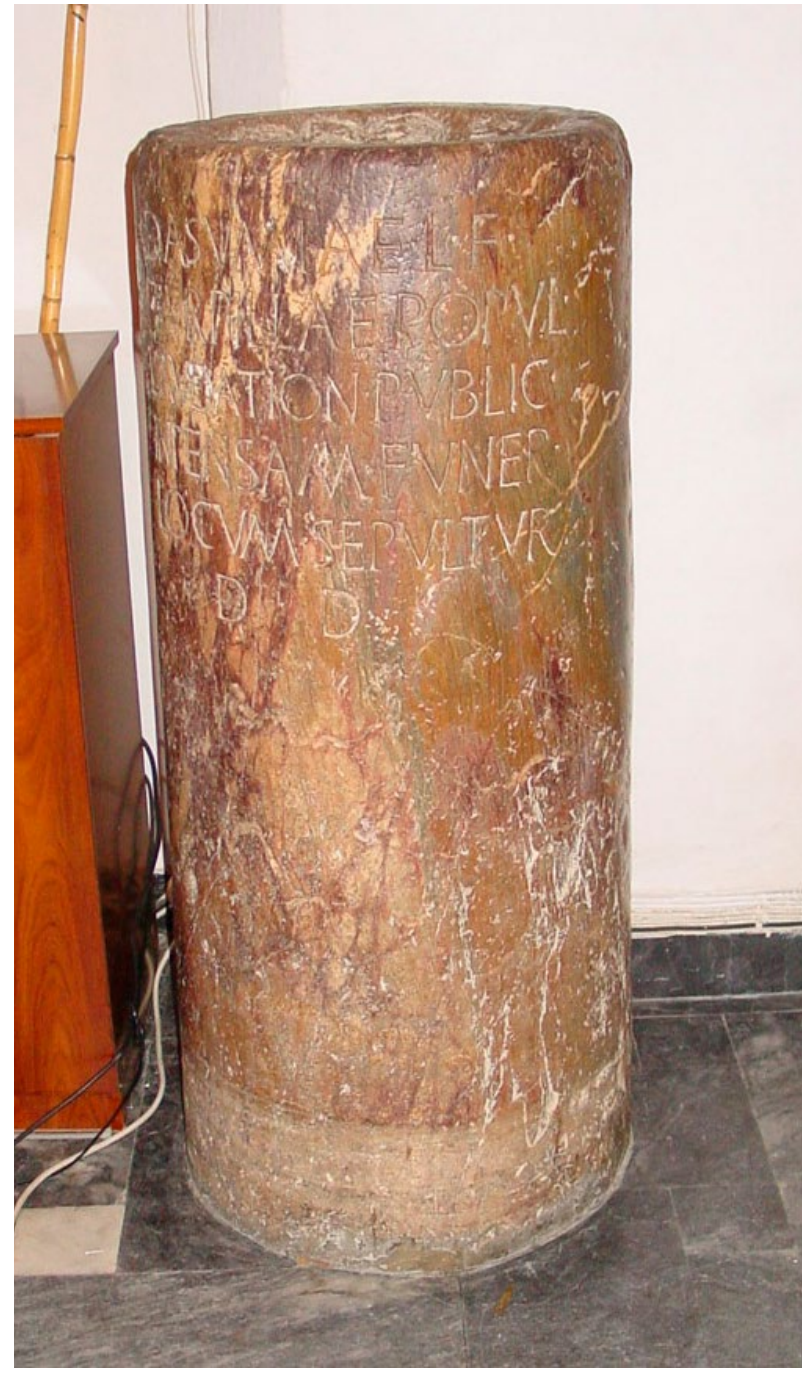

Figura 17: Pedestal cilíndrico reutilizado como pila bautismal conservado en la ermita de San Gregorio Ossetano en Alcalá del Río

señalar que otras investigaciones arqueológicas en la ciudad han parecido poner de manifiesto un uso relativamente temprano de las piedras duras, marmóreas, con fines ornamentales, como es el caso del pavimento de la identificada como curia (Rodríguez Gutiérrez et al., 2012).

4.3.3. Losa de la iglesia de Santa María de Écija (n. ${ }^{\circ}$ 17, Figs. 3 y 4 )

Frente a los ejemplos astigitanos recogidos más arriba, de contexto arqueológico más preciso, la pieza se encuentra actualmente formando parte del atrio de acceso a la iglesia de Santa María. Es una gran losa monolítica de tendencia rectangular, de dimensiones

(CILA) a época trajanea (como ya propusiera la primera edición del CIL): HEp 4, 1994, 697 (A. Canto); De BoscsPlateaux, 2005: 516; Caballos, 2016: 204, lám. 10. 
275 x 145 x $24^{15} \mathrm{~cm}$ (Rodríguez Gutiérrez, 2008: 251; Beltrán y Rodríguez Gutiérrez, 2011: 565, n. 53). No obstante, en su perímetro presenta algunos cortes y entalles artificiales que, por cómo se adaptaron a la nueva ubicación en el atrio, con la inclusión de otras piezas, constata que ya procedieran de un estado anterior. El plano inferior sobre el que actualmente se apoya está desbastado toscamente, lo que parece confirmar su función original, también, como losa de pavimento. En esta pieza se ha podido documentar, en sus casi tres metros de anchura, la enorme variabilidad cromática que puede ofrecer el material en una superficie relativamente limitada. También es la pieza de mayores dimensiones documentada hasta el momento, lo que aporta valiosa información sobre las posibilidades de la explotación y la naturaleza de los afloramientos.

\subsubsection{Miliario de La Luisiana (n. ${ }^{\circ}$ 18, Fig. 18)}

La pieza ingresó en el Museo Arqueológico de Sevilla en 1902, sin mayor precisión sobre el contexto o lugar de hallazgo, genérico en La Luisiana (Sevilla). Es un fuste monolítico de columna de $86 \mathrm{~cm}$ de altura por 26 de diámetro, reutilizado probablemente como miliario

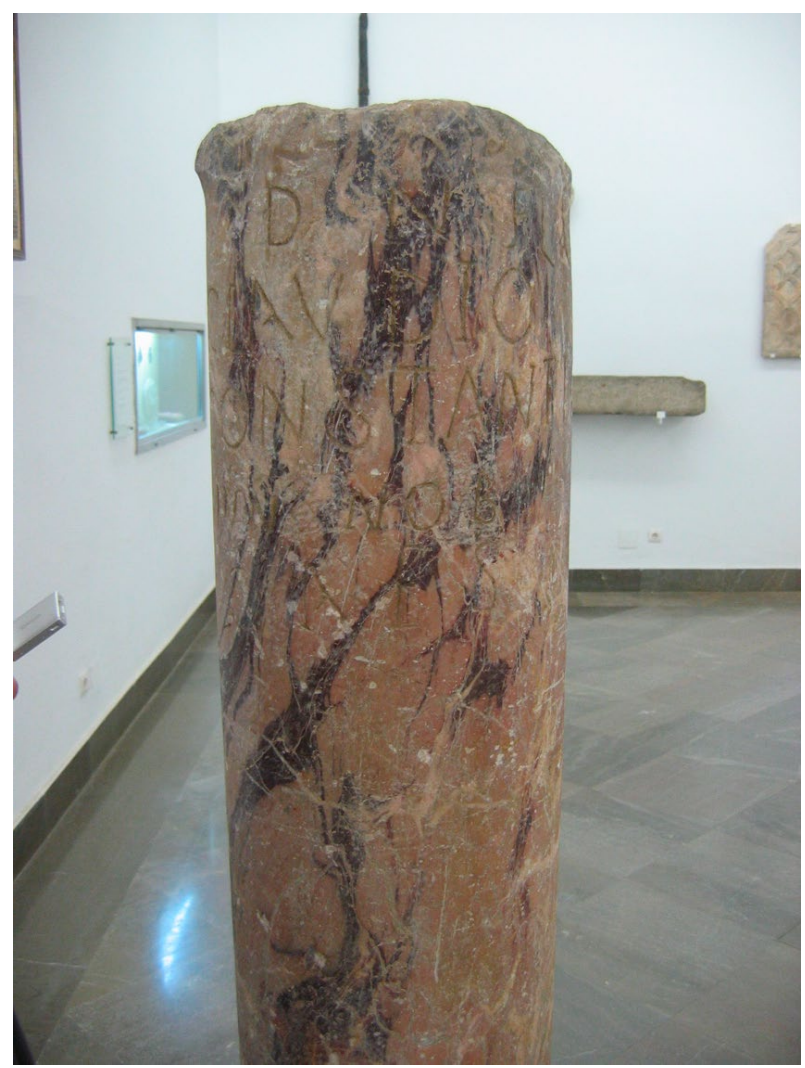

Figura 18: Miliario procedente de La Luisiana

15. El grosor y acabado del bloque en su plano inferior pudieron ser documentados con motivo de las obras de renovación del pavimento de la plaza adyacente, en 2006. en un segundo momento. Está rematado en la parte superior con una doble moldura.

El texto de la inscripción, incluida con motivo de la reutilización de la pieza, con una ordinatio bastante descuidada y un ductus vacilante, se organiza en diez líneas: $D$ (omino) $N($ ostro) / Flau(io) Valerio $\beta$ Constantino / Pio Felic(i) / invict(o) Auug(usto) /o diui Constanti / filio / bono / rei publico / nato (Ordóñez, 1993: 308).

No es posible establecer la datación de la pieza original, de época romana indeterminada. La reutilización, como miliario, se data en el primer cuarto del siglo IV d. C. (310/2-324 d. C.) (Sillières, 1990: 112-114; Ordóñez, 1993: 308).

\section{EMPLEO Y DISPERSIÓN (FIG. 1)}

A partir de los materiales presentados es posible llevar a cabo una serie de valoraciones sobre los usos mayoritarios de esta caliza, así como su principal área de dispersión, a la espera de que el mapa de distribución pueda ampliarse con nuevos hallazgos.

Como ya se ha indicado más arriba, la dureza y compactación de esta piedra la hacen especialmente favorable para la fabricación de elementos monolíticos. Más aún, un grupo numeroso, de diferentes ciudades y edificios, lo constituyen las grandes losas de pavimento. Estas son masivas y de considerable espesor, con tan sólo un mayor cuidado en el desbastado y pulido del plano superior, dejando con un trabajo más tosco el resto; a la economía de trabajo se suma favorecer el agarre entre piezas y a la cama inferior de apoyo. Parece ser un material especialmente idóneo para el enlosado de lugares de intenso paso y localización a la intemperie, como se confirma en el teatro de Itálica o el patio abierto del edificio hispalense de la calle Goyeneta. De menores dimensiones y espesor son las placas documentadas en el forum novum de Corduba, lo que podría confirmar la propuesta de su localización en el interior de la cella del templo frente al temenos exterior perimetral. El material, en contexto, aparece asociado a edificios públicos, de considerable monumentalidad y prestigio. Ello hace de él, por tanto, un material duradero pero a la vez vistoso y mejor valorado desde el punto de vista estético que otras variedades con función semejante, como las ya aludidas piedra cordobesa de mina y gaditana losa de Tarifa. Dentro de una misma unidad geológica es posible, no obstante, que estemos ante densidades de material diferentes que ofrezcan posibilidades alternativas para el trabajo de la piedra, susceptibles de conseguir menores dimensiones y mayor grado de detalle.

Otro grupo de piezas que llama poderosamente la atención en este conjunto son los pedestales cilíndricos epigráficos. Las piezas de Corduba $\left(\mathrm{n}^{\circ}{ }^{\circ} 15\right)$ e Ilipa (n. ${ }^{\circ}$ 16) parecen responder casi al mismo módulo. A ellos cabe añadir, de menor altura y mayor diámetro, el ejemplar de Itálica (n. ${ }^{\circ}$ 6). Esta tipología de piezas 
y lo que es más relevante, los actos honoríficos de los que formaban parte, han sido recientemente abordados por A. Caballos (2016: 194). Según este autor este tipo de homenajes, en forma de estatuas broncíneas con sus correspondientes epígrafes sobre los pedestales cilíndricos, se convirtió en toda una seña de identidad en la provincia Baetica, coincidiendo con el arranque de estos usos en los mecanismos de autorrepresentación de las primeras elites ciudadanas. El modelo parece haberse consolidado en época augustea y en él se perciben incluso guiños a la familia imperial (Caballos, 2016: 212). De hecho, la inexistencia de campo epigráfico delimitado por medio de elementos físicos parece identificarse como rasgo de antigüedad (Caballos, 2016: 195; Navarro, 2017: 440).

En lo que se refiere a la datación, los ejemplos más antiguos con cronología fiable son de época tardoagustea (teatro de Itálica: $n .{ }^{\text {os }} 1-3$ ), a los que pueden sumarse los indicios paleográficos de una serie de inscripciones que redundan en este momento de comienzos del siglo I (n. ${ }^{\text {os }} 4,6,15$ y 16). No obstante, la explotación parece continuar a lo largo de la segunda centuria de acuerdo a una demanda similar, como parece constatarse en la fabricación de losas de pavimento para el edificio de la calle Goyeneta (n. $\left.{ }^{\circ} 7\right)$ o la herma de contexto doméstico de Astigi (n. ${ }^{\circ}$ 9). Los casos de reutilización, que testimonian el valor dado al material a lo largo del tiempo, comienzan ya avanzado el siglo II (n. $\left.{ }^{\circ} 13\right)$, se constatan en época tardoantigua (n. $\left.{ }^{\circ} 10\right)$ y llegan a documentarse en época medieval (n. ${ }^{\text {os }} 14 \mathrm{y}$ 16) y moderna (n. $\left.{ }^{\circ} 17\right)$. Del repertorio analizado y a la espera de nuevos datos nada hace pensar, por tanto, que la explotación hubiera continuado a partir de fines del siglo II d. C.

La dispersión, a su vez, se dibuja en un amplio sector del Valle del Guadalquivir. Un hilo conductor relevante en la distribución y alcance de la explotación parece ser la vía fluvial, con el punto máximo río arriba en Corduba y río abajo en Hispalis. En este circuito queda igualmente incluido el principal afluente del Guadalquivir, el Genil, en cuya margen izquierda se sitúa la ciudad de Astigi, plenamente integrada en esta red, de manos del intenso comercio oleícola en la región y la salida del producto por Hispalis. Alguno de los ejemplares, ocasionalmente, resulta situado en tierras más interiores, como es el miliario hallado en La Luisiana (n. $\left.{ }^{\circ} 18\right)$. Además de tratarse de un caso de reutilización, su localización queda suficientemente justificada por su carácter de hito topográfico.

\section{PROPUESTA DE LOCALIZACIÓN DEL ÁREA DE ORIGEN: MARCO GEOGRÁFICO Y CON- TEXTO GEOLÓGICO}

Se ha llevado a cabo una investigación, de forma paralela a la confección del catálogo, a fin de identificar las zonas que cumplieran con los requisitos planteados y que las hicieran susceptibles de ser la fuente de origen del litotipo aquí analizado. Para ello se ha partido de la caracterización geológica establecida a partir de los diferentes análisis petrográficos, la ubicación hipotética del área de origen propuesta por diferentes autores y el mapa de dispersión de piezas arqueológicas generado en el presente estudio.

A partir de los indicios obtenidos se ha revisado la cartografía geológica del sector, correspondiente al primer escalón de la Sierra Morena de Sevilla, tras superar el valle del Guadalquivir.

En esta zona se produce el contacto entre dos grandes unidades geoestructurales de génesis y constitución bien diferenciada: por un lado, las depresiones neógenas, representadas por la Depresión del Guadalquivir, que se erige como una cuenca receptora de los sedimentos generados por la erosión del Macizo Hespérico, al Norte, y, sobre todo, de las Cordilleras Béticas al Sur, de forma que en su mayor parte alberga sedimentos cenozoicos (neógenos y cuaternarios) que no han sido afectados orogénicamente; y por otro, el Macizo Ibérico, que se pone de manifiesto en nuestro ámbito en Sierra Morena, constituido por materiales precámbricos y paleozoicos plegados durante la orogenia hercínica y que desde entonces han quedado emergidos constituyendo un continente sometido a erosión (Moreira, 2003: 85-88).

Es dentro de los límites de esta unidad, concretamente de la zona de Ossa Morena (ZOM), donde se localiza la zona estudiada (Fig. 19), que queda separada de las zonas Centroibérica y Surportuguesa por grandes fallas de tipo inverso generadas a finales de la orogenia hercínica, así como por cabalgamientos e intrusiones ígneas ${ }^{16}$. Ocupa el $\mathrm{N}$ de las provincias de Huelva (Sierra de Aracena), Sevilla (Sierra Norte), Córdoba (al N del Guadalquivir) y Jaén (Sierra de Andújar). Ossa Morena se caracteriza por: la gran profundidad y variedad de rocas (ígneas o metasedimentarias), presentar grandes extensiones de afloramientos del Precámbrico y del Cámbrico (si bien su estratigrafía abarca desde el Proterozoico Superior al Carbonífero), el notable desarrollo del plutonismo (Santa Olalla, Pedroso, Castilblanco, Santa Elena, etc.) y de series vulcanosedimentarias transformadas metamórficamente en anfibolitas, gneises o esquistos, y la edad de los plegamientos hercinianos principales, que es claramente del Carbonífero Inferior (Julivert et al., 1974: 22-26; Vázquez Guzmán y Fernández Pompa, 1976: 13; Vera, 2004: 25). De hecho, en la Ossa Morena se integran tres de los principales distritos meridionales de marmora explotados en época romana: los de Almadén de La Plata, Alconera y Estremoz. Es, precisamente por ese

16. En cualquier caso, hay que tener en cuenta que no hay un consenso generalizado acerca de sus límites (Gil Cid, 1991; San José et al., 2004), no existiendo acuerdo en el contacto con la Zona Centroibérica (Julivert et al., 1974; Robardet y Gutiérrez-Marco, 2004) ni en el de la Zona Surportuguesa (Crespo, 1987; Julivert et al., 1974; Ábalos, 1988). 


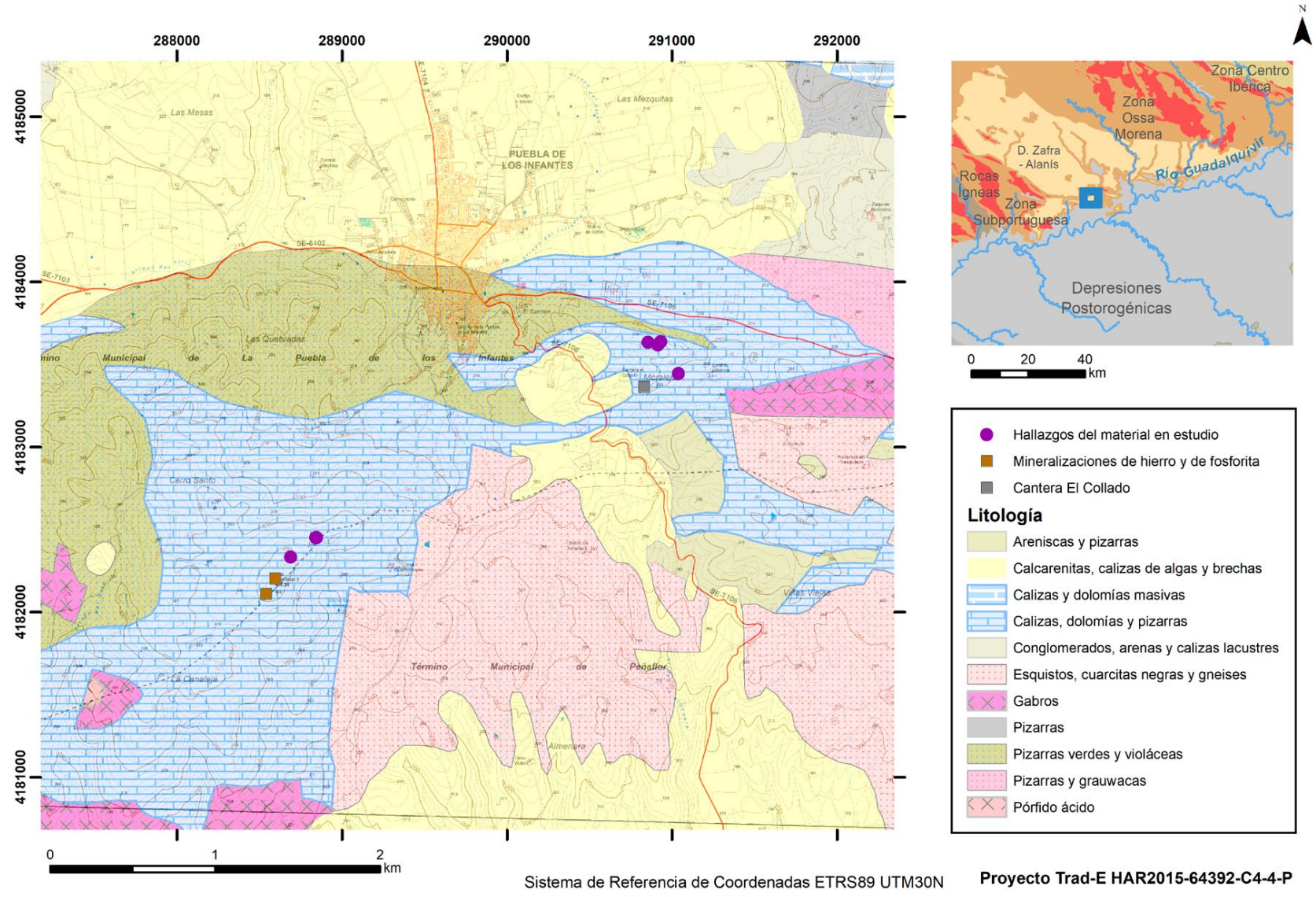

Figura 19: Mapa geológico de la zona de estudio

origen geológico común, por lo que, según qué características, en ocasiones resulta difícil discriminar entre materiales de estas canteras, a las que ahora se suma la caliza polícroma que nos ocupa ${ }^{17}$.

Dada su diversidad y complejidad estratigráfica y tectogénica, se han diferenciado diversos dominios, afectando a nuestra zona de estudio el de Zafra-Alanís (Junta de Andalucía 1985). Abarca el área comprendida entre la falla de Malcocinado y la alineación precámbrica de Olivenza-Monesterio, estructurándose a partir de un conjunto de pliegues que forman un gran sinclinal de directriz general NO-SE y una vergencia hacia el SO, afectado por fallas (como las de la Urbana, de la Fundición o Guadalcanal) que han preservado de la erosión a una serie de pequeñas cuencas carboníferas discordantes, y con extensos afloramientos precámbricos en su flanco NE y paleozoicos desde el Cámbrico Inferior al Devónico en sus partes centrales (Vázquez Guzmán y Fernández Pompa, 1976: 13; Liñán, 1984: 289-290).

Centrándonos en la estratigrafía de la hoja del mapa geológico a escala 1:50.000 correspondiente a la zona

17. De hecho, como ya se ha indicado, ha sido frecuentemente atribuida a niveles de cobertera de Almadén de La Plata (Rodríguez Gutiérrez, 2008: 252), como ejemplo de caliza en ese entorno sometida a diferentes niveles de metamorfismo. de estudio (942, Palma del Río), en muro se encuentran materiales del Cámbrico Inferior, dentro de los cuales se distinguen tres unidades (Pérez Domínguez y Hernán, 1973: 3-8; Vázquez Guzmán y Fernández Pompa, 1976: 32):

1. Cámbrico basal. Aquí, desde el punto de vista litoestratigráfico, se diferencian tres zonas:

- Una inferior, caracterizada por la abundancia en rocas volcánicas (porfiroides y keratófidos cuarzosos) que se intercalan entre los materiales metamórficos (anfibolitas, microgneises y esquistos albíticos).

- Un tramo medio, constituido por esquistos de composición variable y de filitas cuarzo albíticas, con aumento del grado de metamorfismo hacia el sur de la zona, donde destacan los micaesquistos.

- A techo del Cámbrico basal, un tramo detrítico de gran resistencia a la erosión.

2. Cámbrico carbonatado. Los materiales que lo forman son calizas, comúnmente de tipo micrita y que han sufrido un proceso de recristalización muy intenso, y dolomías, muy cristalinas, en contacto mecánico con el resto de los materiales, entre los que destaca el material detrítico, constituido por areniscas cuarzo-feldespáticas y micas (moscovita y biotita cloritizada) y pizarras. 


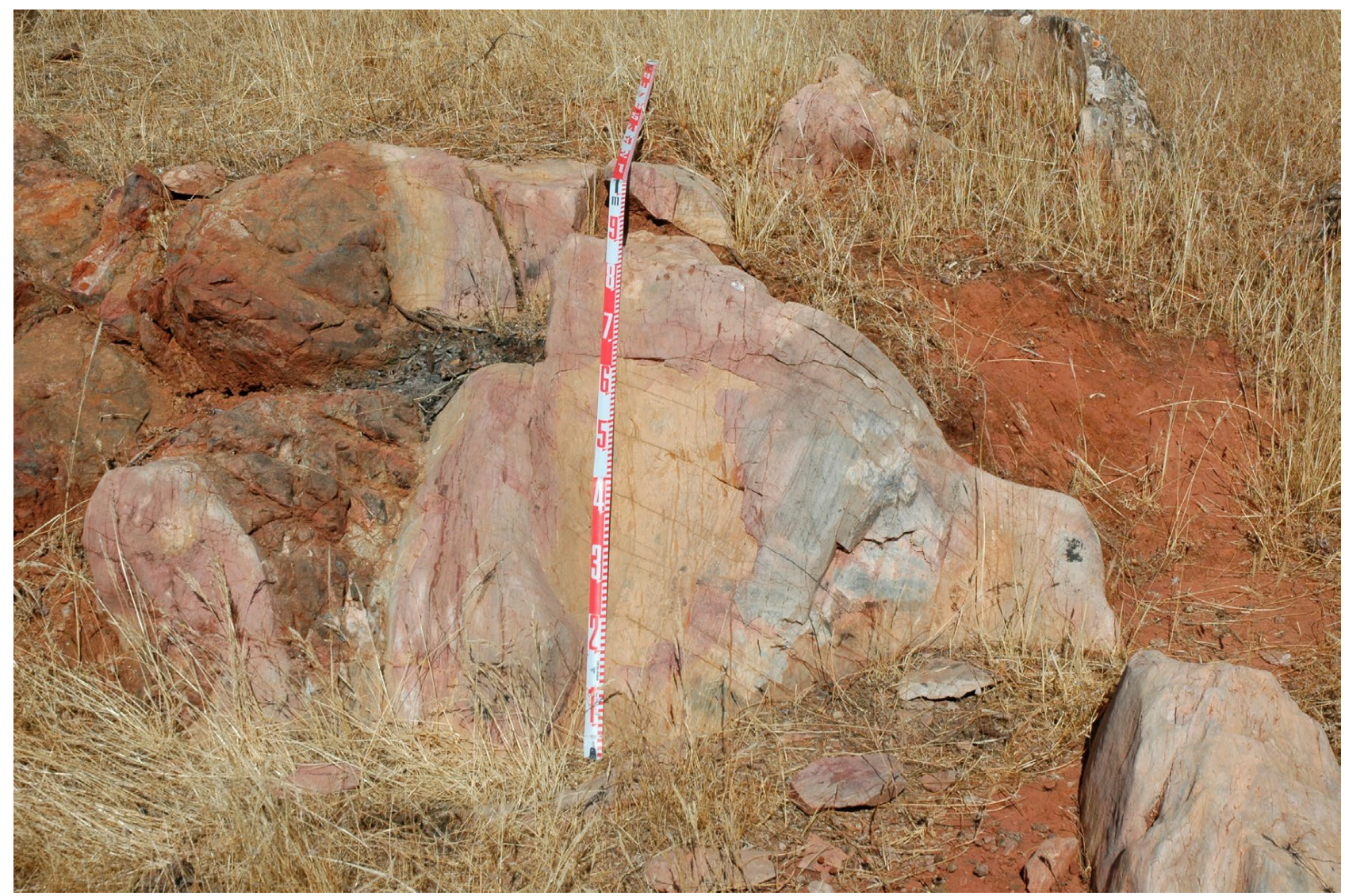

Figura 20: Material en un afloramiento de calizas cámbricas en el término municipal de La Puebla de los Infantes

3. Serie pizarroso detrítica-superior. Aflora en una estructura sinclinal existente en las calizas cámbricas. Los materiales que integran esta unidad son cuarcitas claras y tramos de pizarras violáceas.

Por tanto, es en la serie del cámbrico carbonatado donde se establece el origen de las piezas empleadas en época romana, pues las calizas del Cámbrico Inferior, tras verse afectadas por una tectónica de fractura muy intensa, experimentaron una notable metalogénesis asociada con alteraciones hidrotermales de génesis metamórfica (Calderón, 1886: 139; Díaz del Olmo et al., 1998). Ello dio lugar a mineralizaciones relacionadas con procesos volcano-sedimentarios del ciclo cadomiense de hierro y de fosforita, de tipo estratiforme (Pérez Domínguez y Hernán, 1973: 17; Vázquez Guzmán y Fernández Pompa, 1976: 116; Aizpurúa et al., 1982; IGME, 1986: 10; Gumiel et al., 2008: 6-8; Boixereu et al., 2011: 102-103).

Esta revisión de la naturaleza geológica del área ha permitido plantear, de forma más concreta pero como hipótesis de trabajo, que el área fuente pudiera situarse en el entorno de la actual Puebla de Los Infantes, municipio situado al Norte del curso del río Guadalquivir, en el Noreste de la provincia de Sevilla, próximo al confín con la de Córdoba. De forma más específica, en el área de El Pozuelo y el Cerro Santo, próxima a las Minas de San Cristóbal.
También constaba la localización precisa sobre el territorio de algunas de estas mineralizaciones, como las de las citadas Minas de San Cristóbal Sur y Norte ${ }^{18}$ (Gumiel et al., 2008: indicios 134-76 y 135-76; Boixereu et al., 2011: 290) y de la cantera El Collado, explotación abandonada de calizas y dolomías de las que se extrajeron áridos de machaqueo (Pérez Domínguez y Hernán, 1973: 19; Monteserín y Navarro, 2011: 484). Incluso existían noticias históricas de fines del siglo XIX donde se aludía a la calidad de la piedra y su potencial para la explotación. Así, S. Calderón (1886: 133) la describía como una «caliza arcaica generalmente sacaroidea, de bellísimo aspecto, compacta y homogénea en vastas superficies cuando no ha sufrido influencias metamórficas; pero infiltraciones de hierro y penetraciones de diversos minerales le hacen perder su blancura primitiva ú originan zonas azuladas ó rosadas de tinte suave y que por lo común aumentan su belleza». Por su parte, F. Vázquez Guzmán y F. Fernández Pompa (1976: 37) la describen como una «caliza de tonos claros a rosados (marmorizadas) con débiles intercalaciones pizarrosas verde rojizas». El mismo Calderón (1886) hacía ya referencia a su posible empleo como piedra ornamental, al afirmar que «a

18. Su mineralogía está compuesta de fosforita, hematites, calcita y dolomita, y de forma accesoria, apatito y cuarzo (Boixereu et al, 2011: 290). 
juzgar por su aspecto pudieran emplearse como bellos mármoles, pero no sabemos se apliquen, al menos en la Sierra, más que para la fabricación de cal en pequeña escala, para lo cual también ofrece excelentes condiciones». En el mismo sentido se pronuncian H. Pérez Domínguez y P. Hernán (1973: 19), al enunciar que «el aspecto de las calizas, su dureza y sus tonos, que le prestan una gran vistosidad, hacen pensar en su posible utilización como rocas para ornamentación, pero es muy posible que esto sólo fuera factible en casos muy concretos y determinados de masas continuas $y$ con resistencia suficiente».

Visto todo lo anterior se procedió a llevar a cabo una prospección superficial ${ }^{19}$ en la zona indicada a fin de corroborar la localización del litotipo, obteniéndose un resultado altamente positivo (Fig. 20).

A pesar de la identificación, por tanto, sobre el terreno, de materiales semejantes a los empleados en época romana para la realización de elementos arquitectónicos, estructurales y decorativos, no se ha reconocido, en ningún caso, evidencia de trabajo de extracción antigua. Ello se debe a diferentes factores relacionados con el aparente cese de la explotación ya en época antigua. Las eventuales huellas de extracción que hayan podido sobrevivir de este momento son difícilmente identificables, más aún con la invasión generalizada de vegetación propia de monte bajo. Por otro lado, al no continuar la actividad a cierta escala en época histórica, se produjo la pérdida de las referencias espaciales así como de la propia tradición. Por ello, en el estado actual de la investigación, podemos afirmar que la piedra objeto de este estudio se obtuvo de la región analizada. No obstante, no es descartable ni que las canteras romanas se encontraran en otro lugar próximo de características geológicas semejantes, ni que se tratara de un distrito más complejo con diferentes puntos de extracción dispersos en una mayor extensión. En un futuro será preciso estudiar de forma más intensiva la posibilidad de que exista un mayor número de afloramientos de este litotipo.

\section{VALORACIÓN FINAL}

Es muy posible que en adelante sean muchas más las piezas que se identifiquen realizadas en este material que permitan así ampliar el actual corpus y matizar notablemente la propuesta de dispersión geográfica. De hecho, diferentes noticias orales que no han podido ser contrastadas aún sugieren la existencia de ejemplos también en Carmona. En cualquier caso, se define claramente una circulación favorecida por la vía fluvial

19. Llevada a cabo en agosto de 2018 , en ella participaron quienes esto suscriben así como Antonio D. Navarro (geólogo), Emilio Navarro (arqueólogo) y José María Sánchez (restaurador); a todos ellos agradecemos su inestimable colaboración. del Guadalquivir donde, la totalidad de los ejemplares -salvo el ya citado caso de La Luisiana- se localizan en ciudades bañadas por el río o su principal afluente el Genil. No deja de ser significativo que se pueda documentar un desplazamiento a cierta distancia y una más que probable organización administrativa del transporte fluvial de cargas pesadas con anterioridad a su definitiva consolidación y amplia difusión de manos del comercio del aceite, a partir de época flavia $^{20}$. También se ha insistido ya en el hecho de que, desde momentos tempranos, de en torno al cambio de Era, en una misma obra se den cita materiales lapídeos de muy diferente origen. Ello supondrá una logística desarrollada y una importante organización del abastecimiento para la construcción. En el caso de las piedras ornamentales, además, la presencia coetánea de diferentes variedades en un mismo proyecto lleva a reflexionar no sólo sobre el intencionado valor subjetivo y simbólico de estas selecciones, sino en las eventuales relaciones de los curatores con los puntos de explotación.

El marmor polícromo bético fue un material indudablemente bien valorado tanto desde el punto de vista estético como estructural. Su éxito quizá estribó, precisamente, en un adecuado equilibrio entre ambos aspectos, favorable mientras se contó con la capacidad técnica suficiente para obtener buenos resultados en la resolución de las piezas en el marco de una explotación mínimamente rentable, no necesariamente sólo a efectos económicos. Todo parece indicar, a la espera de nuevas evidencias y mayor número de datos, que la acusada dureza y densidad pudieron limitar su mayor difusión como soporte de prestigio a lo largo del tiempo, a pesar de intentos como el testimoniado por el miliario hallado en La Luisiana, ya del siglo IV.

Desde el punto de vista arquitectónico buena parte de los ejemplos corresponden con edificios públicos de primer orden, destacando el teatro en Itálica, el templo de culto imperial en Corduba o un edificio desconocido pero de notable entidad en Hispalis. Ese ambiente público y de representación y prestigio se vuelve a encontrar en algunos de los ejemplos epigráficos. No obstante, la herma procedente de una domus de Astigi también ilustra que en el mercado regional, con carácter primario, agentes privados pudieron acceder al material; algo que queda fuera de toda duda en los circuitos de reutilización de materiales, como evidencia la losa funeraria conservada en la ermita de Villadiego de Peñaflor.

Un rasgo que refuerza la importancia, calidad y consideración que en época romana debió de tener la caliza

20. Aunque ya con anterioridad, desde comienzos de época augustea se haya documentado el abastecimiento de aceite bético especialmente a los campamentos germanos, en forma de ánforas como pueda ser la Oberaden 83, sin evidencia, no obstante, de puntos de producción y, por tanto, aún de tenue testimonio arqueológico en el área de origen (García Vargas et al., 2011). 
polícroma presentada en este estudio son los ejemplos, escasos pero significativos, de pedestales cilíndricos honoríficos. Estos elementos parecen ser un medio de expresión asociado a unas elites directamente vinculadas a la promoción estatutaria de las ciudades y a la asunción de magistraturas y honores cívicos. En el caso de la caliza polícroma, además, parece que las piezas corresponden a las primeras décadas de consolidación del tipo, cuya difusión continuará en adelante.

La vistosidad del material propició, asimismo, que fuera objeto de reutilización, en una valoración fundamentalmente estética de las piezas. Ya en época antigua ejemplos de dinámicas de reuso parecen ser las losas parietales del foro ecijano, la losa funeraria de Celti o el miliario de La Luisiana. Siglos después aún mantenía su prestigio, como demuestran los fustes y losas pavimentales de la mezquita de Córdoba, el umbral de la iglesia de Santa María de Écija o la pila bautismal de la capilla de San Gregorio de Alcalá del Río.

Ante el desconocimiento de puntos concretos de explotación antigua es solo posible proponer por el momento un área relativamente amplia de origen que, de hecho, se corresponde geológicamente y de forma unívoca con el litotipo estudiado. En ese sentido, nada puede avanzarse sobre la naturaleza de la explotación y su gestión, sobre la eventual existencia de un único distrito o de varios y cómo serían administrados. Las enormes dimensiones de algunas de las piezas arqueológicas documentadas confirman la calidad y amplitud de los frentes.

\section{NOTA SOBRE LAS FUENTES PARA LA PRODUCCIÓN CAR- TOGRÁFICA}

Las figuras-mapa (Figs.1 y 19) han sido elaboradas en el marco del proyecto Trad-E HAR2015-64392-C4-4-P con el software SIG ArcMap 10.4 (ESRI, 2016).

En cuanto a la figura 1, y en concreto, al mapa general de localización del mármol objeto de estudio, en su confección se ha tratado de ser lo más fiel posible a la realidad geográfica de época antigua. En ese sentido, el elemento del relieve que más ha modificado su disposición respecto a la actualidad es la hidrografía, de forma que las capas cartográficas que representan la vega de Sevilla y la desembocadura del Guadalquivir toman como fuente estudios geoarqueológicos (Borja Barrera et al., 2018; Borja, 2018), mientras que para el curso del río Guadalquivir hasta Córdoba se ha reconstruido siguiendo a M. Ponsich $(1974,1979)$, quien establece la vinculación entre el río y los alfares.

También se ha considerado necesario incluir, con vistas a una completa representación cartográfica, el resto de la red hidrográfica a partir de fuentes actuales (IECA, 2017) aunque no esté constatado su trazado en época romana.

Por otra parte, para el relieve se han despreciado los cambios que ha podido sufrir éste, por lo que se ha optado por un Modelo Digital del Terreno (de $200 \mathrm{~m}$, dada la amplitud del área de difusión del material empleado) referido a época actual (IGN, 2009).

A partir de Sillières (1990) se han digitalizado tanto el viario, como los núcleos, optando en este caso únicamente por aquellos cuya existencia es reconocida de forma unánime.
Asimismo, los límites conventuales han sido digitalizados a partir de la TIR (1995; 2002).

En lo que respecta a la figura 19, para la elaboración del mapa principal se han digitalizado aquellas unidades geológicas que distinguen Pérez Domínguez y Hernán (1973), tomando su simbología de la cartografía geológica digital continua a escala 1:50.000 (GEODE) creada por el IGME (http://info.igme.es/visorweb/). Por su parte, el mapa de contexto geológico se ha creado a partir de IECA (2017), y en la representación se ha optado por seguir aquellas tramas comúnmente aceptadas en el ámbito científico de la geología en lo que se refiere a las edades de los materiales.

\section{REFERENCIAS}

Ábalos, B. (1988). El límite entre la zona de Ossa-Morena y la zona Surportuguesa. Evidencias y propuestas sobre su posición y significado (Macizo Hercínico Ibérico). Estudios Geológicos, 44, 405-414.

Àlvarez, A., Domènech, A., Lapuente, M. P., Pitarch, Á. y Royo, H. (2009). Marbles and Stones of Hispania. Tarragona: Institut Català d'Arqueologia Clàssica.

Àlvarez, A., Pitarch, Á., Gutiérrez García-Moreno, A. y Rodà, I. (2006). Informe del análisis de un conjunto de materiales lapídeos de Itálica (Santiponce, Sevilla). (Documento técnico inédito). Tarragona: Institut Català d'Arqueologia Clàssica.

Aizpurúa, J., Gumiel, P. y Pineda, A. (1982). Introducción al estudio de los yacimientos de fosfatos del Macizo Ibérico Meridional. Boletín Geológico y Minero, 93(5), 390-414.

Barresi, P. (2003). Province dell'Asia Minore. Costo dei marmi, architettura pubblica e committenza. Roma: L'Erma di Bretschneider.

Beltrán, J. (2003). Las esculturas. En J. Beltrán. y J. R. López Rodríguez (Eds.). El museo cordobés de Pedro Leonardo de Villacevallos (pp. 119-148). Madrid-Málaga: Servicio de Publicaciones Universidad de Málaga.

Beltrán, J. (2004). La colección Villacevallos: historia de un «Museo» Arqueológico del XVIII en Córdoba. Mus-A: Revista de los museos de Andalucía, 4, 100-111.

Beltrán, J., Loza, M. L., Ontiveros, E., Rodríguez Gutiérrez, O., Taylor, R. (2011). La explotación y el empleo de Marmora en la Baetica. Un proyecto de investigación de base arqueométrica. Revista Itálica. Revista de Arqueología Clásica de Andalucía, 1, 51-75.

Beltrán, J. y Rodríguez Gutiérrez, O. (2011). Los materiales lapídeos de la Provincia Baetica: estado de la cuestión y líneas actuales de investigación. En S. Camporeale, H. Dessales y A. Pizzo (Eds.). Arqueología de la construcción II. Los procesos constructivos en el mundo romano: Italia y las provincias orientales (pp. 555-570). Mérida: CSIC.

Beltrán, J. y Rodríguez Gutiérrez, O. (2018). Hispalis republicana y altoimperial a través de los datos arqueológicos. En J. Beltrán y O. Rodríguez Gutiérrez (Eds.). Sevilla arqueológica. La ciudad en época protohistórica, antigua y andalusi (2. ${ }^{a}$ ed., pp. 164-217). Sevilla: Editorial Universidad de Sevilla. 
Beltrán, J., Rodríguez Gutiérrez, O., López Aldana, P., Ontiveros, E. y Taylor, R. (2012). Las canteras romanas de mármol de Almadén de La Plata (Sevilla). En V. GarcíaEntero (Ed.). El marmor en Hispania: explotación, uso y difusión en época romana (pp. 253-275). Madrid: UNED.

Boixereu, E., Gumiel, P. y Feixas, C. (2011). Descripción de las mineralizaciones de la Zona de Ossa-Morena. En A. García-Cortés (Ed.): Cartografía de recursos minerales de Andalucía (pp. 83-108). Madrid: IGME-Consejería de Economía, Innovación y Ciencia, Junta de Andalucía.

Borja Barrera, F. (2018). Geoarqueología urbana en Sevilla. En J. Beltrán y O. Rodríguez Gutiérrez (Eds.). Sevilla arqueológica. La ciudad en época protohistórica, antigua y andalusi (2. 'ed., pp. 333-369). Sevilla: Editorial Universidad de Sevilla.

Borja Barrera, F., Borja Barrera, C., Jiménez Sancho, A. y García Vargas, E. (2018). Evolución de la llanura aluvial del bajo Guadalquivir durante el Holoceno medio-superior. Geoarqueología y reconstrucción paleogeográfica de la vega de Itálica (Sevilla, España). Boletín Geológico y Minero, 129(1-2): 371-420. DOI: https://www.doi.org/10.21701/ bolgeomin.129.1.015

Caballos, A. (2016). Mutación de los referentes provinciales romanos entre Ulterior y Baetica. Del Bellum Hispaniense a la expresión honorífica de las nuevas elites cívicas en la provincia. En F. Marco, F. Pina y J. Remesal (Eds.). Autorretratos. La creación de la imagen personal en la Antigüedad (pp. 187-212). Barcelona: Universitat de Barcelona.

Calderón, S. (1886). La Sierra de Peñaflor (Sevilla) y sus yacimientos auríferos. Anales de la Sociedad Española de Historia Natural, 15, 131-154.

Chic, G. (1975). Inscripciones de Peñaflor, Habis, 6, 357-363.

Crespo, A. (1987). El Macizo de Aracena (Macizo Ibérico Meridional): Propuesta de división sobre la base de nuevos datos estructurales y petrográficos. Boletín Geológico y Minero, 98(4), 507-515.

Des Boscs-Plateaux, F. (2005). Un parti hispanique à Rome? Ascension des élites hispaniques et pouvoir politique d'Auguste à Hadrien, 27 av. J.-C. - 138 ap. J.-C. Madrid: Casa de Velázquez.

De Nuccio, M. y Ungaro, L. (Eds.) (2002). I marmi colorati della Roma imperiale. Venezia: Marsilio.

Díaz del Olmo, F., Baena, R. y Álvarez, G. (1998). Karst y paleokarst de Sierra Morena (Sector Ossa-Morena, Hespérico Meridional). En J. J. Durán y J. López Martínez (Eds.). Karst en Andalucía (pp. 87-92). Madrid: Instituto Tecnológico y Geominero de España.

ESRI (2016). ArcMap v. 10.4. Environmental Systems Research Institute, Redlands, California.

Fant, J. C. (1993). The Roman imperial marble trade: a distribution model. En R. Francovich (Ed.). Archeologia delle attività estrattive e metallurgiche (pp. 71-96). Firenze: All'Insegna del Giglio.
Fishwick, D. (1991). The Imperial Cult in the Latin West. Studies in the Ruler Cult of the Western Provinces of the Roman Empire, t. II.1. EPRO. Leiden: Brill.

García-Dils, S., Ordóñez, S. M., Conlin, E., Saquete, J. C. y Sáez, P. (2006). La casa de las hermae de Astigi. Habis, 37, 349-364.

García Vargas, E., de Almeida, R y González Cesteros, H. (2011). Los tipos anfóricos del Guadalquivir en el marco de los envases hispanos del siglo I a. C. Un universo heterogéneo entre la imitación y la estandarización. Spal, 20, 185-283. DOI: http://dx.doi.org/10.12795/spal.2011.i20.12

Garriguet, J. A. (2002). El culto imperial en la Córdoba romana: una aproximación arqueológica. Córdoba: Diputación de Córdoba.

Gil Cid, M. D. (1991). Caracterización paleontológica del Cámbrico de la zona de Ossa Morena (Z.O.M.) y sus paleorrelaciones con Marruecos y Centroeuropa. Boletín Geológico y Minero, 102(1), 3-18.

Gimeno, H. y Stylow, A. (2003). Las inscripciones. En J. Beltrán y J. R. López Rodríguez (Eds.). El museo cordobés de Pedro Leonardo de Villacevallos (pp. 149-218). MadridMálaga: Servicio de Publicaciones Universidad de Málaga.

González Acuña, D. (2011). Forma Urbis Hispalensis. El urbanismo de la ciudad romana de Hispalis a través de los testimonios arqueológicos. Sevilla: Servicio de Publicaciones Universidad de Sevilla.

Gumiel, P., Locutura, J. y Montero, J. (2008). Mapa Metalogenético del sector NO de la hoja 76 (Córdoba) E. 1:200.000. Madrid: IGME.

Gutiérrez Deza, M. I. (2007). Los opera sectilia cordobeses. Córdoba: UCO Press.

Gutiérrez Deza, M. I. (2012). Aproximación a los materiales pétreos de la gran arquitectura de Colonia Patricia Corduba. En V. García-Entero (Ed.). El marmor en Hispania: explotación, uso y difusión en época romana (pp. 299-314). Madrid: UNED.

IECA (2017): Datos Espaciales de Referencia de Andalucía (DERA) www.juntadeandalucia.es/institutodeestadisticaycartografia/DERA/ (Consultado el 10 de marzo de 2019).

IGME (1986). Posibilidades auríferas en la zona PeñaflorLora del Rio. Madrid: Secretaría de la Energía y Recursos Minerales, Ministerio de Industria y Energía.

IGN (2009). MDT200 centrodedescargas.cnig.es/ CentroDescargas/index.jsp (Consultado el 10 de marzo de 2019).

Julivert, M., Fonboté, J.M., Ribeiro, A y Conde, L.. (1974). Mapa tectónico de la Península Ibérica y Baleares, E. 1:100.000. Madrid: IGME.

Junta de Andalucía (1985). Mapa geológico-minero de Andalucía. Sevilla: Consejería de Economía e Industria.

Keay, S., Remesal, J. y Creighton, J. (2001). Celti (Peñaflor). La arqueología de una ciudad hispanorromana en la Baetica: prospecciones y excavaciones 1987-1992. Sevilla: Consejería de Cultura Junta de Andalucía. 
Lapuente, M. P., Nogales, T., Royo, H. y Brilli, M. (2014). White marble sculptures from the National Museum of Roman Art (Mérida, Spain): sources of local and imported marbles. European Journal of Mineralogy, 26(2), 333-354. DOI: https://doi.org/10.1127/0935-1221/2014/0026-2369

Liñán, E. (1984). Introducción al problema de la Paleogeografía del Cámbrico de Ossa Morena. Cuadernos do Laboratorio Xeolóxico de Laxe, 8, 283-314.

López Rodríguez, J.R. (2003). Formación y disposición de sus colecciones. En J. Beltrán y J. R. López Rodríguez (Eds.). El museo cordobés de Pedro Leonardo de Villacevallos (pp. 93-114). Madrid-Málaga: Servicio de Publicaciones Universidad de Málaga.

Loza, M. ${ }^{\text {a }}$ L. y Beltrán, J. (2018). El uso de los travertinos calcíticos en las provinciae Tarraconensis y Baetica. Una aproximación general. En J. Beltrán et al. (Eds.). Marmora Baeticae. Usos de materiales pétreos en la Bética romana. Estudios arqueológicos y análisis arqueométricos (pp. 137156). Sevilla: EUS.

Mayer, M. y Rodà, I. (1999). El brocatello de Tortosa: testimonios arqueológicos. Pallas, 50, 43-52.

Monteserín, V. y Navarro, R. (2011). Rocas y minerales industriales. En A. García-Cortés (Ed.). Cartografía de recursos minerales de Andalucía (pp. 367-538). Madrid: IGME-Consejería de Economía, Innovación y Ciencia, Junta de Andalucía.

Moreira, J. M. (2003). El relieve y las costas andaluzas I. Las grandes unidades del relieve andaluz. En A. López Ontiveros (Coord.). Geografia de Andalucía (pp. 81-117). Barcelona: Ariel Geografía.

Navarro Caballero, M. (2017). Perfectissima femina. Femmes de l'élite dans l'Hispanie romaine. Bordeaux: Ausonius.

Ordóñez, S. M. (1993). Una inscripción de Constantino en el Museo Arqueológico de Sevilla. En J. F. Rodríguez Neila (Ed.). Actas del I Coloquio de Historia Antigua de Andalucia, Córdoba 1988. II (pp. 305-310). Córdoba: Monte de Piedad y Caja de Ahorros de Córdoba.

Padilla, A. (2000). Una aproximación a la explotación y la distribución del mármol en el Imperio romano durante los siglos I-II. Habis, 31, 219-233.

Pensabene, P. (1994). Le vie del marmo. I blocchi di cava di Roma e di Ostia: il fenomeno del marmo nella Roma antica. Roma: Ministero per i Beni Culturali.

Pensabene, P. (2002). Il fenomeno del marmo nel mondo romano. En M. De Nuccio y L. Ungaro (Eds.). I marmi colorati della Roma imperiale (pp. 3-67). Venezia: Marsilio.

Pensabene, P. (2013). I marmi della Roma antica. Roma: Carocci ed.

Peña, A. (2009). Análisis del reaprovechamiento de material en la Mezquita Aljama de Córdoba. En Th. G. Schattner y F. Valdés (Eds.). Spolien um Umkreis der Macht. Spolia en el entorno del poder (pp. 247-272). Mainz am Rhein: Diputación Provincial de Toledo - Instituto Arqueológico Alemán de Madrid.
Peña, A. (2010). Estudio de la decoración arquitectónica romana y análisis del reaprovechamiento de material en la Mezquita Aljama de Córdoba. Córdoba: UCO Press.

Pérez Domínguez, H. y Hernán, P. (1973). Mapa geológico y memoria de la Hoja $n^{\circ} 942$ (Palma del Río). Mapa geológico de España E. 1:50.000 (2 $2^{\text {a }}$ Serie MAGNA). Madrid: IGME.

Ponsich, M. (1974): Implantation rurale sur le bas Guadalquivir, T.I: Sevilla-Alcalá del Río-Lora del RíoCarmona. Paris: De Boccard.

Ponsich, M. (1979): Implantation rurale sur le bas Guadalquivir, T.II: La Campana-Palma del Río-Posadas, Paris: De Boccard.

Portillo, A. (2018). El forum novum de Colonia Patricia. Madrid: CSIC

Polichetti, A. (2001). Figure social, merci e scambi nell'Edictum Diocletiani et Collegarum De Pretiis Rerum Venalium. Napoli: Edizioni Scientifiche italiane.

Robardet, M. y Gutiérrez-Marco, J. C. (2004). The Ordovician, Silurian and Devonian sedimentary rocks of the Ossa-Morena Zone (SW Iberian Peninsula, Spain). Journal of Iberian Geology, 30, 73-92.

Rodà, I. (1997). Los mármoles de Itálica. Su comercio y origen. En A. Caballos y P. León (Eds.). Italica MMCC. Actas de las Jornadas del 2200 Aniversario de la Fundación de Itálica (Sevilla 8-11 noviembre de 1994) (pp. 155-180). Sevilla: Consejería de Cultura, Junta de Andalucía.

Rodríguez Gutiérrez, O. (2004). El teatro romano de Itálica. Estudio arqueoarquitectónico. Madrid: UAM Ediciones.

Rodríguez Gutiérrez, O. (2008). Los marmora en el programa arquitectónico y decorativo del teatro romano de Itálica: antiguas hipótesis, nuevas propuestas y posibles certezas a la luz de las aportaciones de los análisis de microscopía óptica de polarización. En T. Nogales y J. Beltrán (Eds.). Marmora hispana: explotación y uso de los materiales pétreos en la Hispania romana (pp. 231-259). Roma: L'Erma di Bretschneider.

Rodríguez Gutiérrez, O. (e.p.a). Comercio y abastecimiento de materiales para la construcción en los procesos de monumentalización de las ciudades romanas, con especial referencia a la Hispania meridional. En Le marché des matières premières dans l'Antiquité et le Moyen Âge. Roma.

Rodríguez Gutiérrez. O. (e.p.b). The prestige of marmor in the architecture of Roman Baetica: local stones vs. imported marbles. Proceedings of the XIX CIAC. Bonn.

Rodríguez Gutiérrez, O., Mañas, I. y Ontiveros, E. (2012). The opus sectile of the curia of Ilipa (Alcalá del Río, Seville). Considerations on the use of stone in public architecture from Roman Baetica. En A. Gutiérrez, P. Lapuente e I. Rodà (Eds.): Interdisciplinary Studies on Ancient Stone. Proceedings of the IX ASMOSIA Conference (Tarragona 2009) (pp. 127135). Tarragona: Institut Català d'Arqueologia Clàssica.

Rodríguez Gutiérrez, O., Rodríguez Azogue, A. y Fernández Flores, A. (2007). Nuevos datos para la caracterización arqueológica de la vida municipal en la Bética: primeras 
notas en torno a un edificio público documentado en la antigua Ilipa (Alcalá del Río, Sevilla). Habis, 38, 225-247.

Russell, B. (2013). The Economics of the Roman Stone Trade. Oxford: Oxford University Press.

San José, M. A. de, Herranz, P. y Pieren, A. P. (2004). A review of the Ossa-Morena Zone and its limits. Implications for the definition of the Lusitan-Marianic Zone. Journal of Iberian Geology, 30, 7-22.

Sillières, P. (1990). Les voies de communication de l'Hispanie méridionale. Paris: Centre Pierre Paris.

Taylor, R., Rodríguez Gutiérrez, O., Ontiveros, E., Loza, M. L., Beltrán, J. y Rodríguez, A. (2018). The value of marble in Roman Hispalis: contextual, typological and lithological analysis of an assemblage of large architectural elements recovered at n. ${ }^{\circ} 17$ Goyeneta Street (Seville, Spain). En D. Matetić y K. Marasović (Eds.). Interdisciplinary Studies on Ancient Stone. Proceedings of the XI Asmosia Conference (Split 2015) (pp. 29-39). Split: Arts Academy in Split.

TIR (1995). Tabula Imperii Romani. Hoja J-29, Lisboa (Emerita, Scallabis, Pax lulia, Gades). Madrid: CSIC.

TIR (2002). Tabula Imperii Romani. Hoja J-30, Valencia (Corduba, Hispalis, Carthago Nova, Astigi). Madrid: CSIC.
Vázquez Guzmán, F. y Fernández Pompa, F. (1976). Contribución al conocimiento geológico del Suroeste de España en relación con la prospección de depósitos de magnetitas. Madrid: Instituto Geológico y Minero de España.

Ventura, Á. (1996). El abastecimiento de agua a la Córdoba romana. II. Acueductos, ciclo de distribución y urbanismo. Córdoba: Universidad de Córdoba.

Ventura, Á. (1999). El teatro en el contexto urbano de Colonia Patricia (Córdoba): ambiente epigráfico, evérgetas y culto imperial. Archivo Español de Arqueología, 72, 57-72.

Ventura, Á. (2002). Ambiente epigráfico del teatro. En A. Ventura, C. Márquez, A. Monterroso y M. A. Carmona (Eds.). El teatro romano de Córdoba (pp. 123-132). Córdoba: Universidad de Córdoba.

Vera, J. A. (Ed.). (2004). Geología de España. Madrid: SGE-IGME.

Ward Perkins, J.B. (1992). Materials, Quarries and Transportation. En H. Dodge y B. Ward Perkins (Eds.). Marble in Antiquity: Collected Papers of J. B. Ward Perkins (pp.13-22). Archaeological Monographs of the British School at Rome, 6. Roma: British School at Rome.

Wilson, A. (2012). Raw materials and energy. En W. Scheidel (Ed.). The Cambridge Companion to the Roman Economy (pp. 133-155). Cambridge: Cambridge University Press. 